\title{
درجة رضا طلبة جامعة عمان الأهلية \\ عن خدمات التسجيل في جامعتهم
}

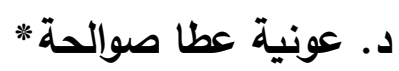

المقدمة

تتوعت المؤسسات التربوية التي يعتمد عليها المجتمع في نشر ثقافته

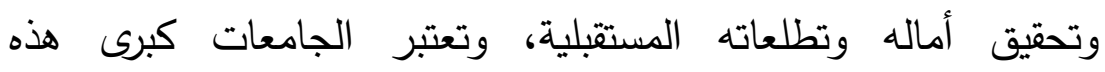

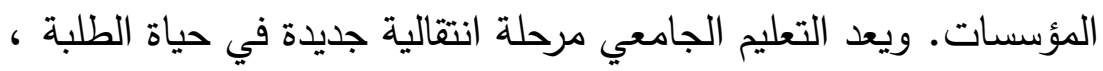
تختلف في معالمها ونظامها وأسلوب تعليمها عن المرحلة الدراسية السابقة

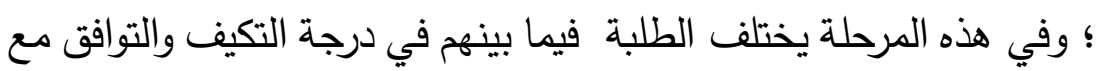
متطلبات هذه المرحلة الدراسية الجديدة فقد تصطدم حاجاتهم مع متطلبات المرحلة الجامعية التي تطبق نظام الساعات المعتمدة لتخريج طلبتها

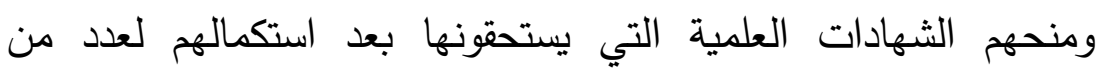

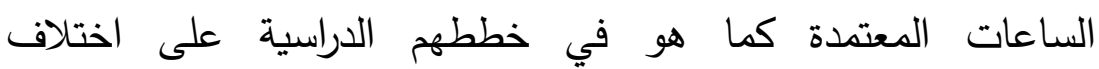

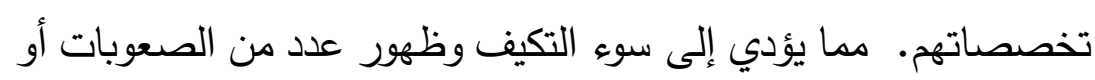

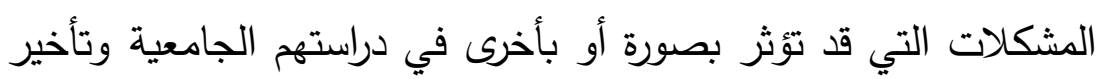
تخرجهم عما هو متوقع. ولتخطي هذه الصعوبات ونجاح نظام الساعات المعتمدة في الجامعة استحدثت عملية الإششاد الأكاديمي، التي تسبق اجراءات التسجيل وكلتا

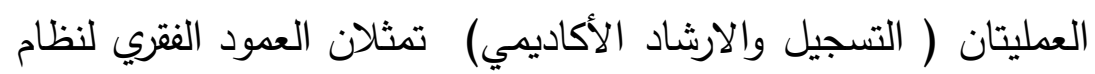
الساعات المعتمدة، وبدونها يصعب تطبيق هذا النظام بشكل فعال. (شهاب،1986 ) 
وقد يرافق عمليتي التسجيل والارشاد الأكاديمي مجموعة من

الممارسات من جانب المرشد الأكاديمي تارة، ومن جانب إجراءات التسجيل التي يقوم بها موظفو دائرة القبول والتسجيل في الجامعة تارةً

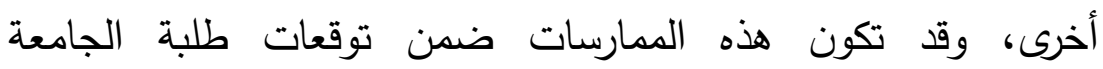

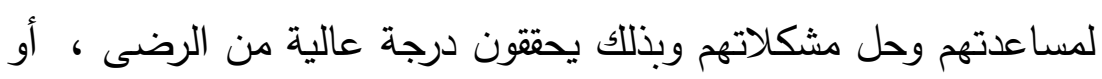
قد لاتكون ضمن التوقعات ولا تساعدهم في حل مشكلاتهم مما يقلل درجة الرضى لديهم.

وهذا ما حاولت الدراسة الحالية التركيز عليه وهو تعرف درجة لرهم رضا طلبة جامعة عمان الأهلية عن خدمات التسجيل في الجامعة. مشكلة الاراسة

تجلت مشكلة الدراسة في الكثف عن درجة رضا طلبة جامعة عمان الأهلية عن خدمات التسجيل في جامعتهم ، وقد تحددت مشكلة البحث من خلال عمل الباحثة في التدريس الجامعي لسنوات طويلة وعملها مديرة مركز التربية الخاصة في الجامعة لفترة زمنية ومقابلتها لعدد من الطلبة وسماعها لشكواهم وتأخر تخرجهم بسبب مشاكل لها لها

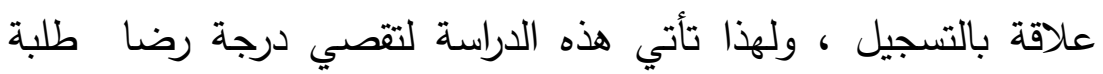

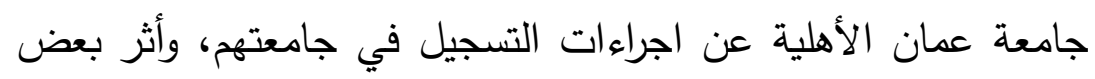

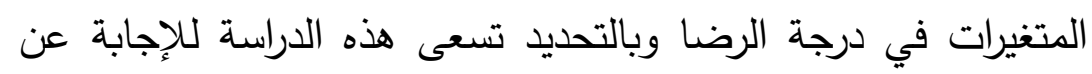

1 - ما درجة رضا طلبة جامعة عمان الأهلية عن اجراءات التسجيل

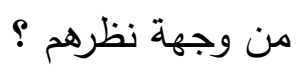

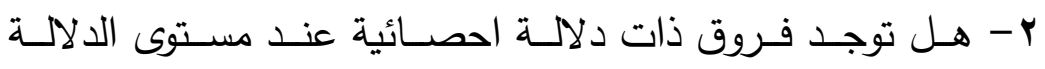

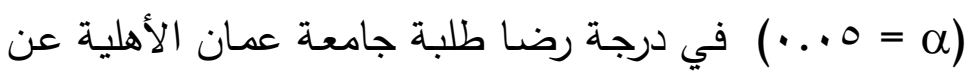




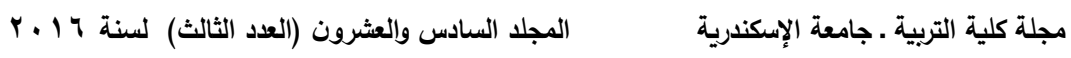

اجراءات التسجيل ، من وجهة نظر الطلبة تعزى لمتغيرات الكلية، و سنوات الدراسة، و الجنسية ؟

أهداف الاراسة سعت هذه الدراسة الى تحقيق الأهداف الأتية:

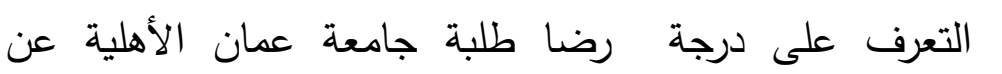
خدمات التسجيل في جامعتهم. التعرف على تأثير متغيرات (نوع الكلية، عدد سنوات الدراسة،

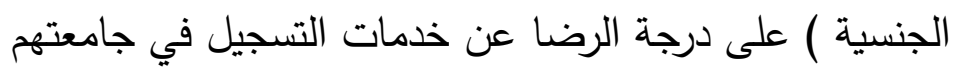

أهمية الدراسة

يمكن تلخيص أهمية البحث بالنقاط الأتية: يتوقع أن تساهم نتائج هذه الدراسة في تطوير الخدمات الجامعية الخدية

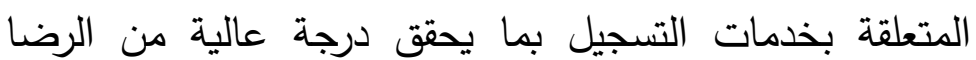
لدى طلبة جامعة عمان الأهلية . قياس درجة رِضا طلبة الجامعة عن اثثين من الخدمات الجامعية وهما خدمات التسجيل لابرازنقاط الضعف.

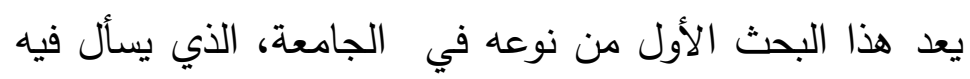

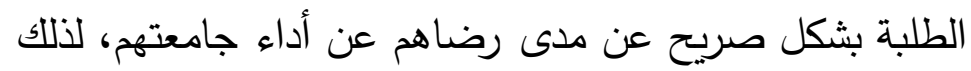
يتوقع أن يسهم في زيادة الوعي بأهمية رِضا الطلبة عن الخدمات الجامعية وجودة التعليم المقدم لهم. تعريف المصطلحات اجراءات التسجيل هي عبارة عن الخطوات التي يقوم بها الطالب لاختيار عدد من المقررات لفصل دراسي ما طبقًا لخطته الدراسية، وذلك بمساعدة مرشده الأكاديمي .ولا تتم هذه العملية بشكل دقيق إلا باعتمادها من جانب المرشد 
الأكاديمي، ومرورها بالإجراءات التي تحددها دائرة القبول والتسجيل، ومن ثم تسليمها لهذه الدائرة ليصبح تسجيل الطالب رسميًا. مقياس درجة الرضا عن اجراءات التسجيل

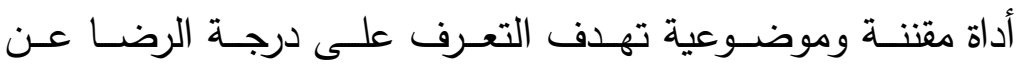

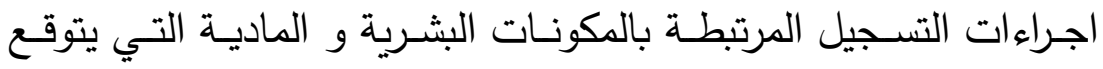
طلبة جامعـة عمان الأهلية وجودها وممارستها لتحقيق مزيد من التقدم الدراسي والراحة النفسية بالجامعة

\section{التعريف الإجرائي لمفهوم رضا الطلبة}

هو تقدير الطلبة لمستوى رضاهم من خلال إجابتهم على فقرات مقياس الرضا عن اجراءات التسجيل من وجهة نظرهم. محددات الدراسة

عند تعميم نتائج هذه الدراسة يجب أخذ المحددات الآتية بعين الاعتبار :

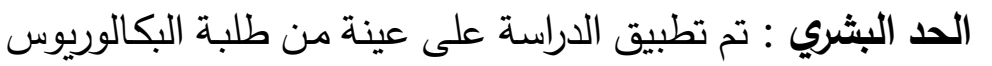

$$
\text { في جامعة عمان الأهلية }
$$

الحـ الزمـاني :تم تطبيق الدراسة في الفصل الدراسي الأول للعام

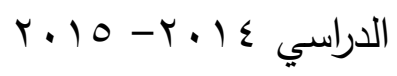

الحد المكاني :أجريت هذه الدراسة في جامعة عمان الأهلية

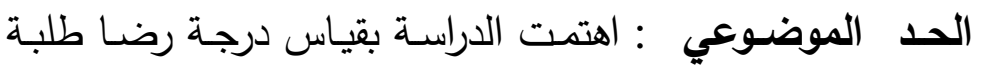
جامعة عمان الأهلية عن اجراءات التسجيل في الجامعة الهدي كذللك تحددت عناصر التسجيل بما ورد في أداة الدراسة أدبيات الدراسة

يقصد برضى الطالب اقتناعها بجودة خدمات التسجيل التي تسبق الخدمات التعليمية المقدمة له في البيئة الجامعية، وثقته بها وتفاعله معها

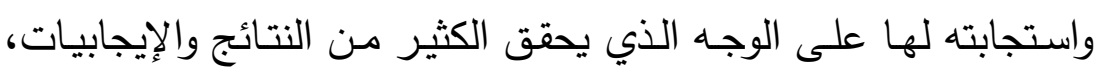

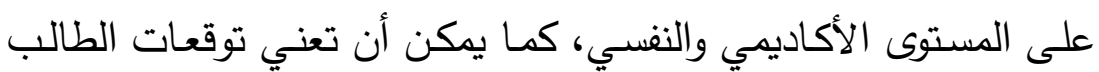


حول شكل ونوع وجودة الخدمات التي سيحظى بها في الجامعة التي من

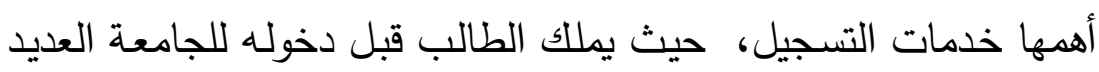
من التصورات الذي يتوقع رؤيتها حقيقة في الجامعة، وبالتالي فإن عدم

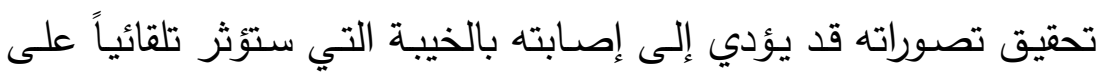

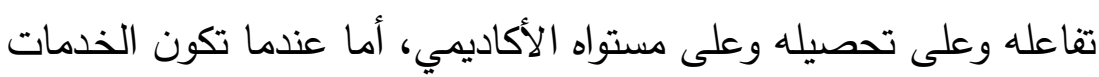
الجامعية المتوفرة متوافقة إلى حد ما مـع تصورات الطالب وتوقعاته فإنهـ سيثـعر بالرضـى وسـينعكس رضــاه على تفاعلـه الجـامعي وتحصـيله الأكاديمي والجدير بالذكر أن رضى الطالب يعد من أهم العوامل التي وني

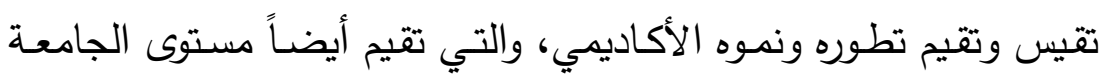

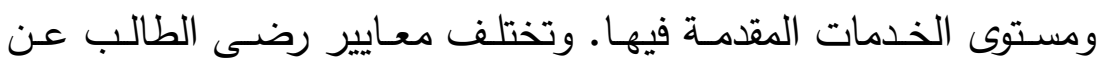
خدمات التسجيل من جامعة لأخرى ومن طالب لآخر ومن نمط تعليمي

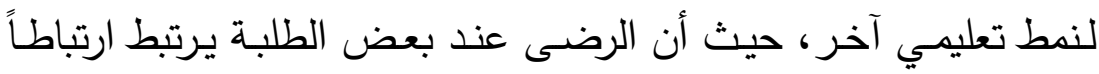

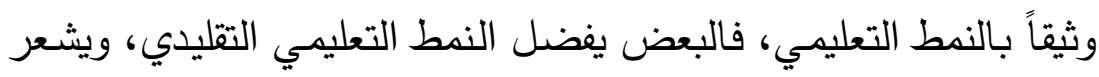

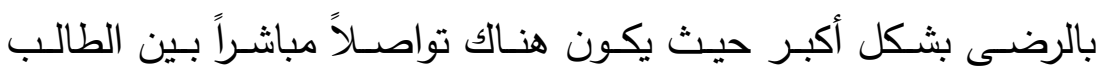

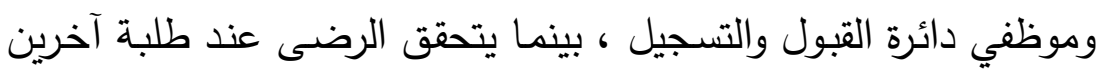

بتطبيق نظام التسجيل الإكتروني (Bolliger\&Martindalc,2004) إن قياس رضى الطلبة أمر استراتيجي بالنسبة للجامعات، لأنه شبيه

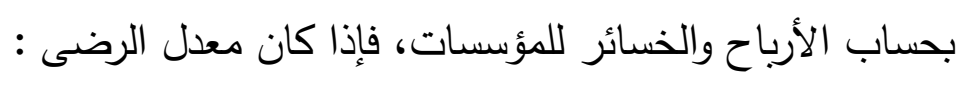

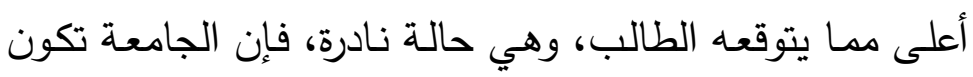

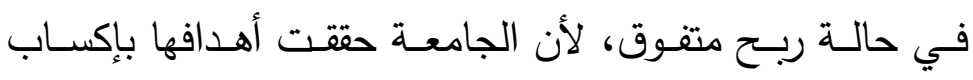

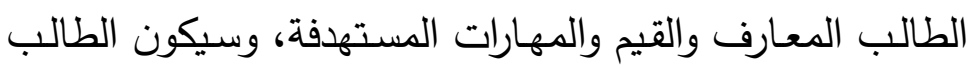

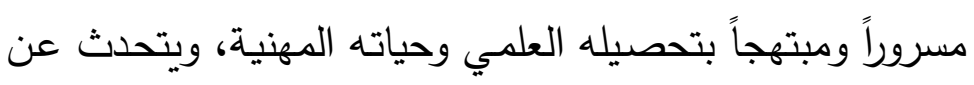

$$
\text { الجامعة بشكل إيجابي. }
$$

أقل من المتوقع، فإن الجامعة في حالة خسارة، لأن الجامعة لم

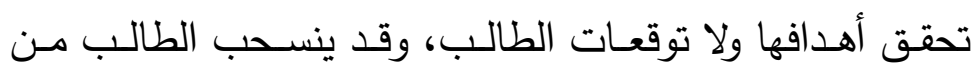


الدراسـة، أو ينتقـل إلـى جامعـة أخـرى، أو يبقـى في الجامعـة ويتعامل معها بشكل سلبي.

مسـاوي لما يتوقعهـ الطالب، فالجامعـة في حالـة استقرار وربح

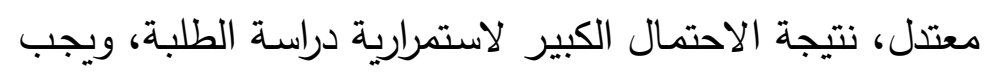

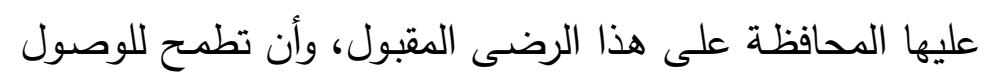

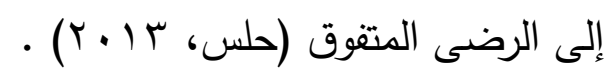

ويمكن قياس الرضا عن الخدمات الجامعية بما فيها خدمات التسجيل التهات

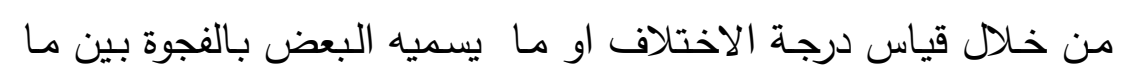
يحققه الطلبة من الخدمة وتوقعاتهم لها. جامعة عمان الأهلية وخدمات التسجيل

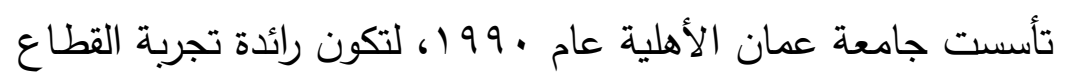

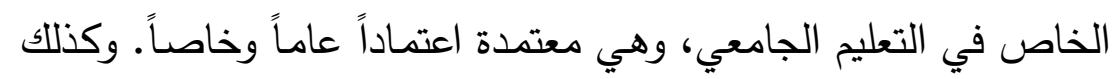
هي عضو في اتحادات الجامعات العربية والإسـلامية والعالمية. وبكونها

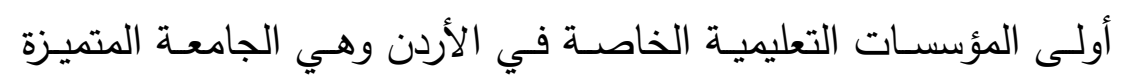

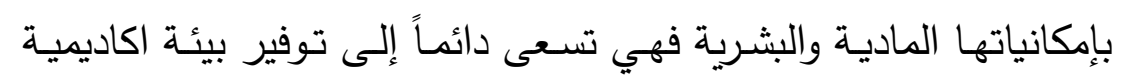

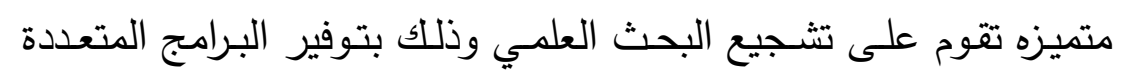

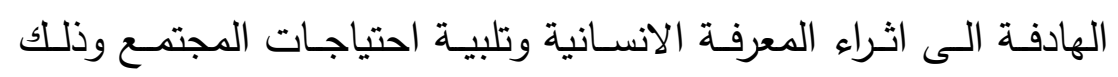

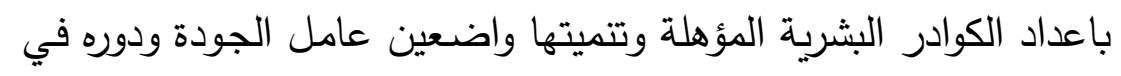
تحقيق الأهداف على الوجه الأكمل في مقدمة الأولويات، اذ ان التركيز

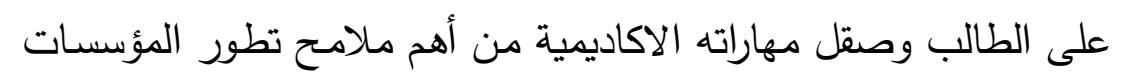
التعليمية وتميزها.

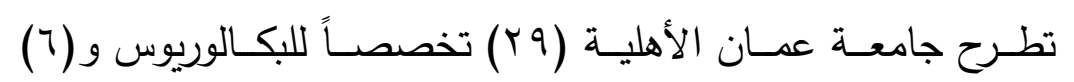

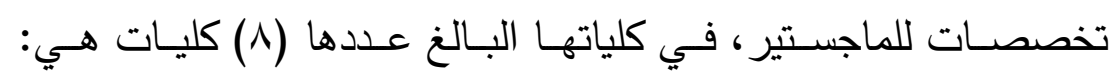

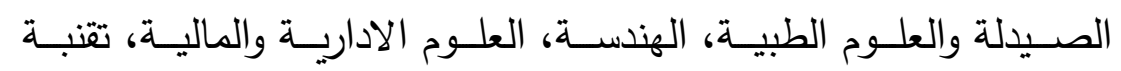
المعلومات، العمارة والتصميم، الآداب والعلوم، الحقوق، التمريض. ولئه وفيها 
ما يزيد عن (Y0. عضو هيئة تدريس يعملون بتفرغ كامل الى جانب

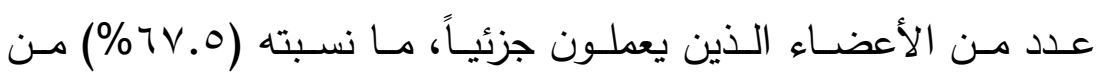

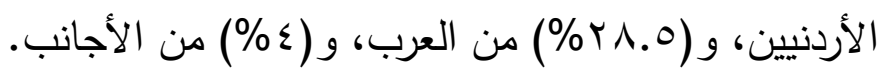

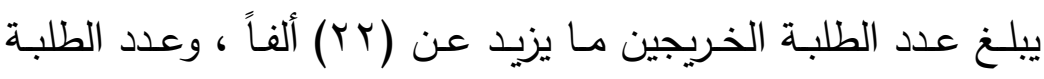

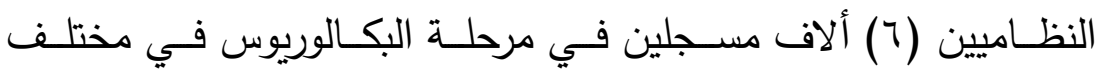
التخصصات العلمية والأدبية.

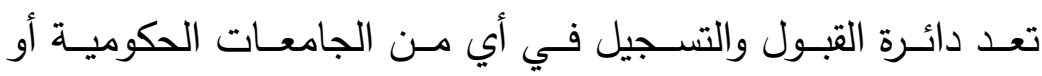

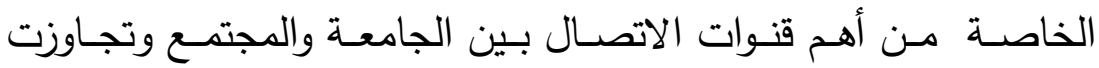
بأعمالها الحدود التقليدية ولم تعد تقتصر على الأنشطة والأعمال الإدارية

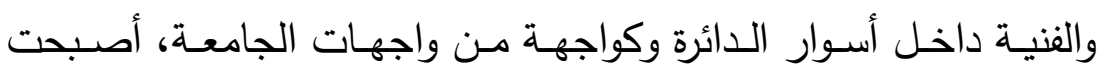
الـائرة تلتقي بـالجمهور ويلتقي بها الجمهور وعلى أبوابها تبـدأ حيـاة

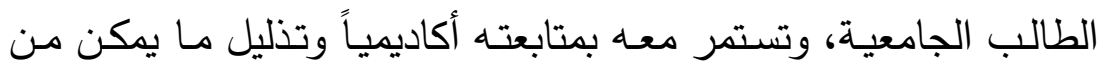

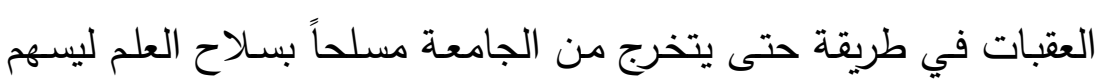
في بناء الوطن بما تحصل عليه من علم ومهارة مدة دراسته الجامعية.

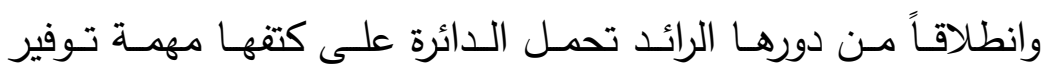

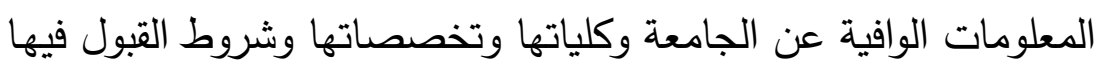

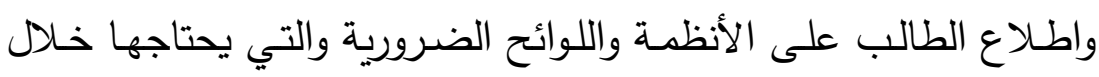

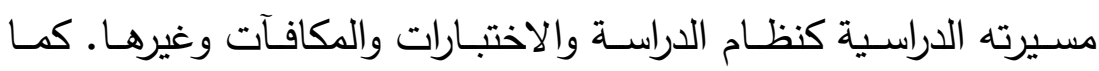
تستقبل الطلاب والزائرين من مختلف المدارس بشكل مستمر .وتسعى الـائرة إلى متابعـة التطـورات الحديثـة في إجـراءات القبـول والتسـجيل

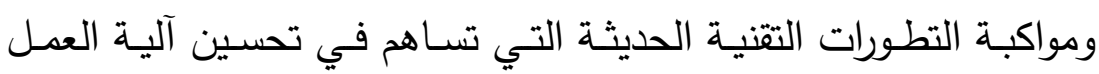
وانجاز المهام وتبسيط الإجراءات والتحول نحو بيئة العمل الالكترونية.

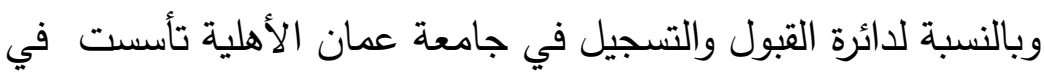
عـام • 199 مـع تأسـيس الجامعـة والتـي تعدل على تطـوير الوسـائل المناسبة لاستقطاب الطلبة واستكمال إجراءات القبول وتطبيق نظام منح 
درجـة البكـالوريوس على الطلبـة، وكـذللك اســتخدام أفضـلـل الوسـائل التكنولوجية من أجهزة كمبيوتر وأنظمة تسجيل متطورة مع استخدام شبكة ونس

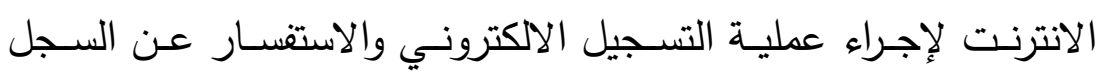
الأكاديمي للطالب وتسعى الدائرة لتفعيل عملية الإرشاد الكترونياً.

تسعى الدائرة من خلال عملها تحقيق الأهداف التالية : ا ـ قبول الطلبة من مختلف الثقافات والجنسيات r. تسجيل المواد الفصلية للطلبة وفقاً للخطط الدراسية المعتمدة بسهولة وسرعة ودقة .

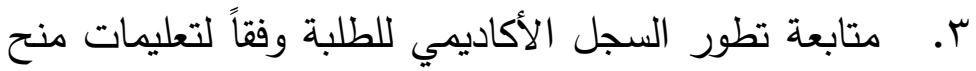

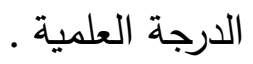
ء. ضمان تطور السجل الأكاديمي للطلبة وفقاً لتعليمات منح الدرجة العلمية . - المون ه. الحفاظ على السجل الأكاديمي بشكل سري وآمن .

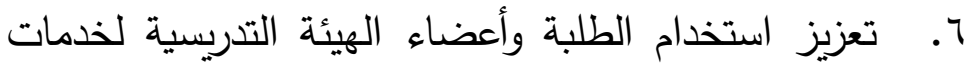
القبول والتسجيل الإكترونية . تصنيز V. توفير بيانات دقيقة وآمنة ومتطورة لمختلف الكليات والدوائر في الجامعة والجهات ذات العلاقة . A. تنمية مهارات العاملين في الدائرة وتطويرها . 9. مواكبة التطور التكنولوجي المتنامي في مجالات القبول والتسجيل . • 1. الرقابة الداخلية المستمرة لكافة إجراءات القبول والتسجيل . تتكون دائرة القبول والتسجيل في جامعة عمان الأهلية من الأقسام الأتية: قسم القبول والتسجيل ويشمل: • • شعبة القبول

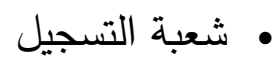


قسم الوثائق والمعلوماتية ويشمل:

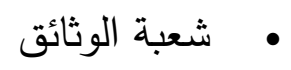

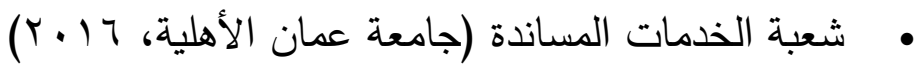

وبمتابعة مسيرة الطلبة التعليمية نجد أن الخدمات التي تقدمها دائرة

القبول والتسجيل من أهم الخدمات الجامعية بكافة مستوياتها.

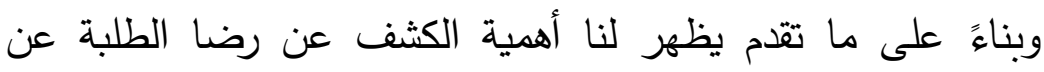

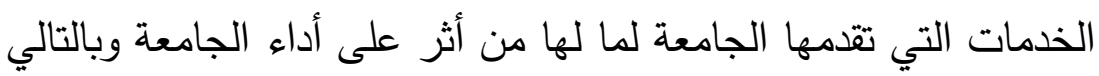
تحقيق أهدافها، وعليه تأتي هذه الدراسة لقياس درجة رضا طلبة جامعة أترات

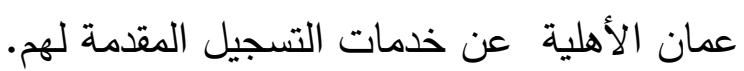
الاراسات السابقة

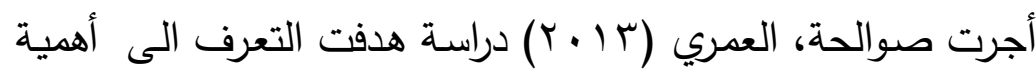

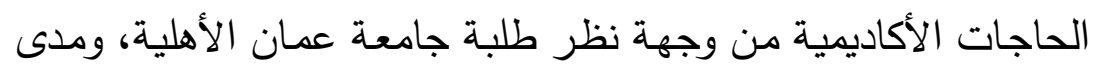
رضاهم عن تحقيقها وفقاً لأربعة مجالات تتعلق ب: بالهئ لهيئة التدريسية،

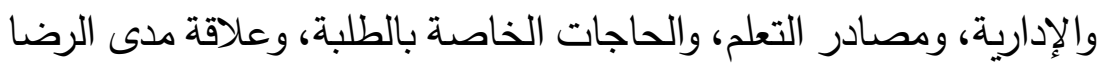
عن تحقق الحاجات بمتغيرات : الجنس، نوع الكلية، السنة الدراسية ، ( r 10$)$ والجنسية ـ تم اختيار عينة الدراسـة والبالغ عددها

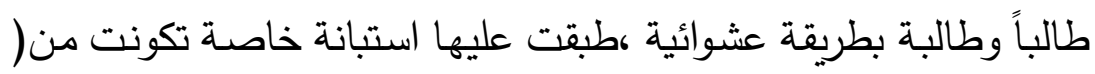

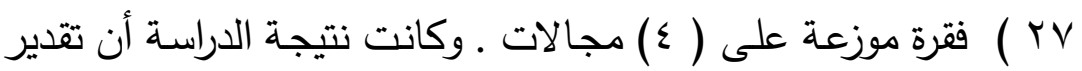
الطلبة لأهمية الحاجات الأكاديمية في الجامعة عموماً كان (متوسطاً)،

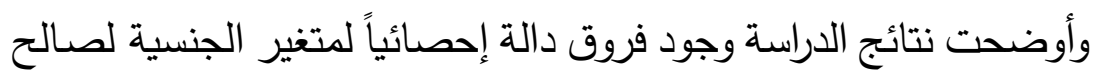

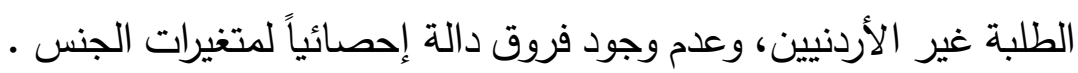

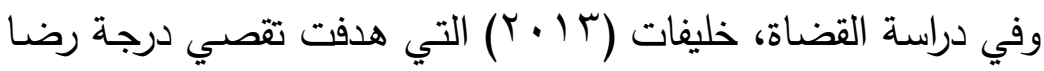
طلبة جامعة مؤتة عن الخدمات الجامعية، ولتحقيق ذلك تم إعداد استبانة

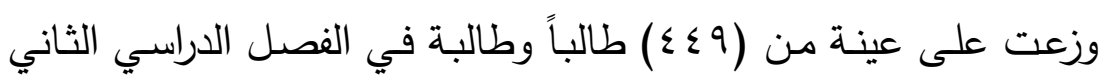

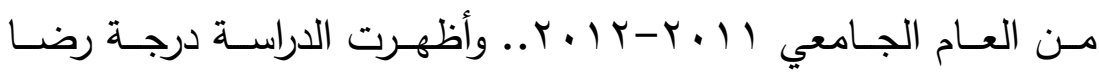


متوسطة للطلبة على أداة الدراسة ومجالاتها، وكثفت النتائج عن فروق

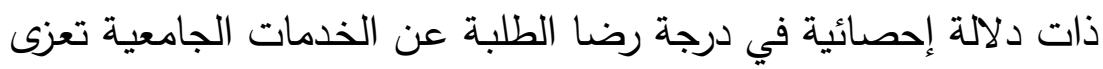

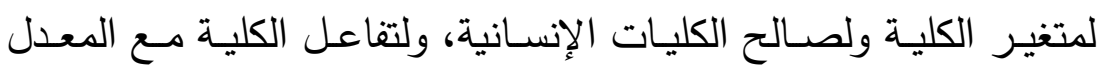
التراكمي لصالح الكليات الإنسانية عند ذوي المعدل التراكمي ممتاز وجيد جداً، ولصالح الكليات العلمية عند ذوي المعدل التراكمي مقبول. وظهرت

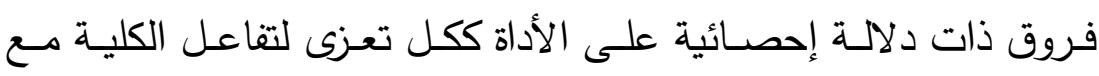
المعدل التراكمي لصالح طلبة الكليات الإنسانية ، ولصالح طلبة الكليات

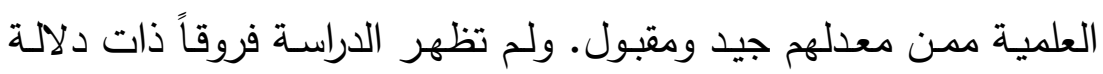
إحصائية تعزى لمتغير الجنس.

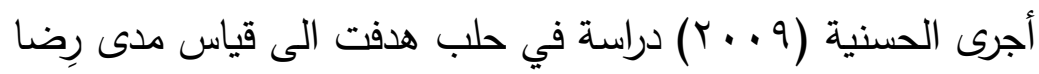
طلبة كلية الاقتصاد في جامعة حلب عن مستوى الأداء الإداري المتمثل بخدمات التسجيل والأكاديمي المتمثل بالارشاد الاكاديمي لكليتهم ، وقد الإدي أستخدمت الاستبانة كأداة للقياس على عينة مؤلفة من 290 طالباً وطالبة في مرحلة البكالوريوس والدراسات العليا، وقد بينت النتائج أن المستوى مرئ

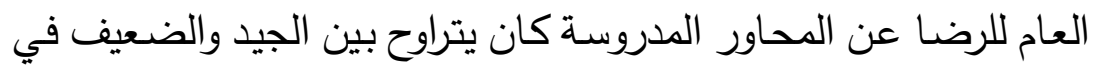

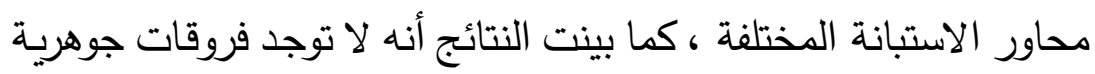

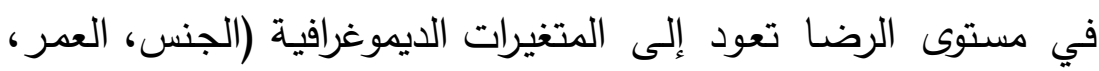
الحالة الدراسية، نوع الثهادة الثانوية، مكان الإقامة، سنوات الدراسة).

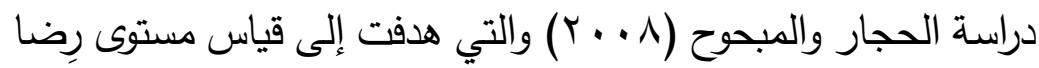
طلبة جامعة الأقصى في فلسطين عن جودة خدمات التسجيل والإرشاد

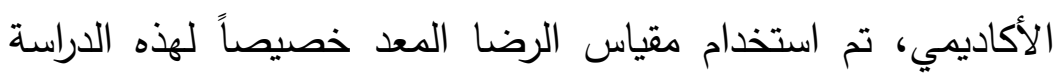

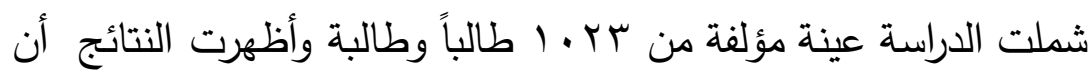
المستوى العام لرِضا الطلبة كان متوسطاً، بمعدل يتراوح حول ـ ج \% لثلاثة

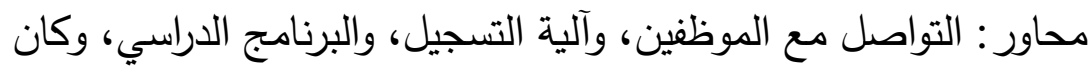

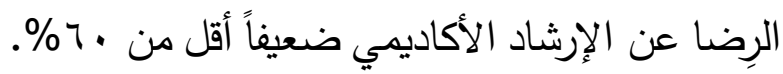


دراسة عبد المحسن تقي وآخرون (1 . . r) والتي هدفت تعرف مستوى الرضا عن جودة الخدمات التعليمية في جامعة الكويت والتعليم التطبيقي

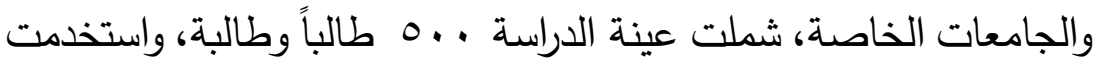

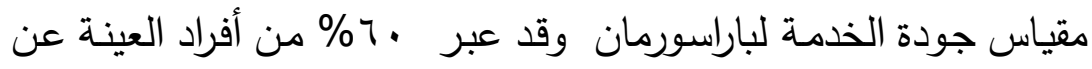

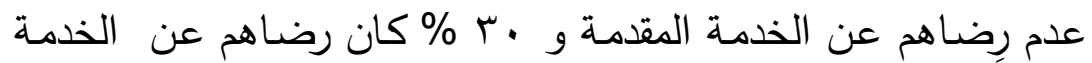

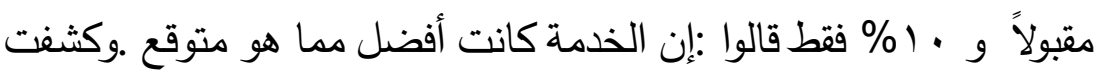

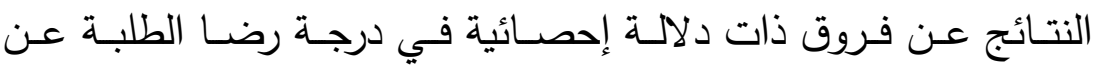

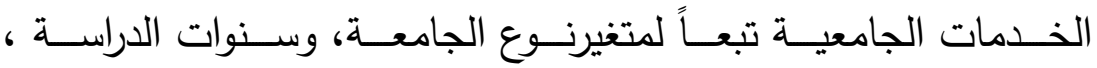

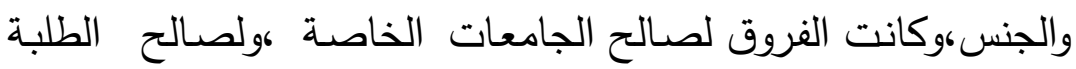
المستجدين ولصالح الذكور •

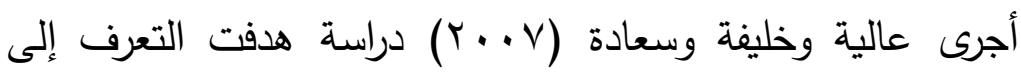
المشكلات التي يواجهها طلبة جامعة الاسراء الخاصة ، والناجمة عن إجراءات التسجيل ، والمرشد الأكاديمي ، وأثر متغيرات الجنس،و لكلية

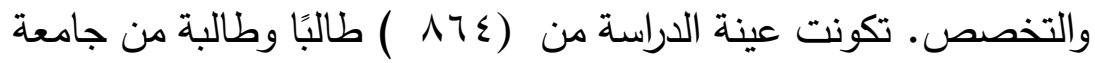

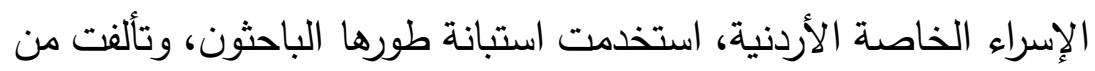

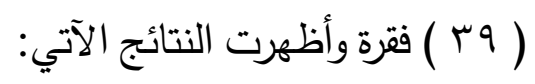
- أن غالبية المشكلات المتعلقة بإجراءات التسجيل كانت حادة جدًا من وجهة نظر الطلبة. - أن أكثر المشكلات حدة المتعلقة بالمرشد الأكاديمي عدم وجود فروق ذات دلالة إحصائية تعزى لمتغيري،الجنس، والكلية

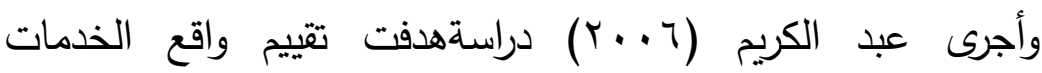
الارشادية الطلابية في مؤسسات التعليم العالي بسلطنة عمان على عينة قوامها (·؟Y) طالبة في التخصصات العلمية والأدبية. أشارت نتائج الدراسة أن رضا طالبات التخصصات العلمية أعلى من التخصصات واتهات التهات التصات 
الأدبية ، وأن هناك قصوراً في تقديم الخدمات الارشادية والمساعدة في حل المشكلات الدراسية ووجود فجوة بين الطالبات والمدرسين. الاراسات الأجنبية

أجريت دراسة (McGhie, 2009) هدفت الى تحديد احتياجات طلاب الاجبه

السنة الأولى في كلية الاقتصاد والعلوم الإدارية في جامعة كيب الغربية جنوب أفريقيا، والتحديات التي تواجهمر ودور أعضاء هيئة التدريس في الإسي

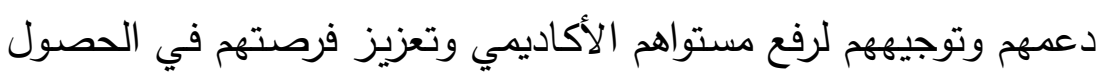

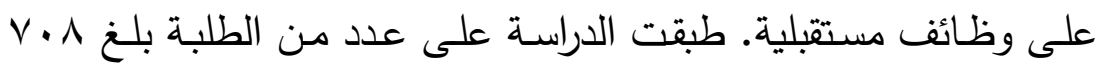

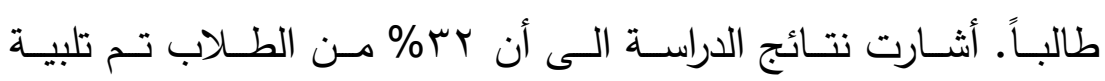
احتياجاتهم في عملية التعلم

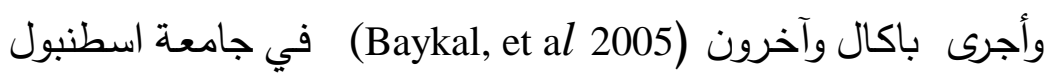

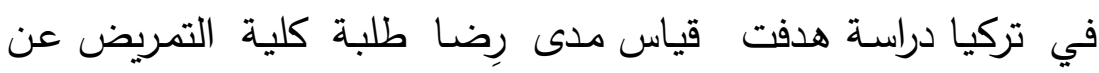

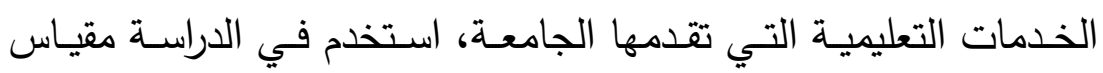

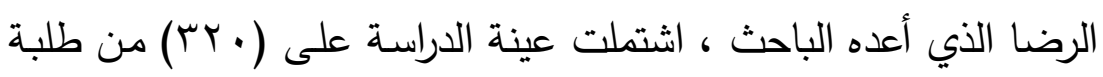

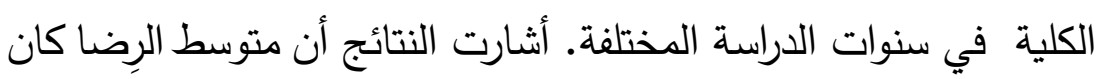

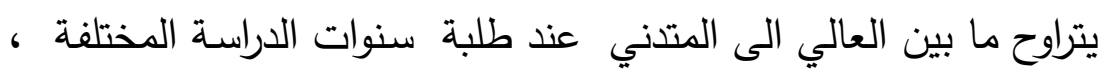

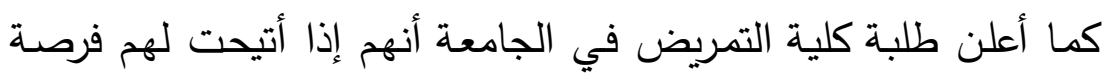
الاختيار فسوف يختارون اختصاصاً آخر وذلك لأن الكلية أخفقت في تلبية رغباتهم وتلبية حاجاتهم. كما أجرى كارا ودوشيلد ( الولايات المتحدة دراسة هدفت التعرف على مستوى رِضا طلبة إدارة

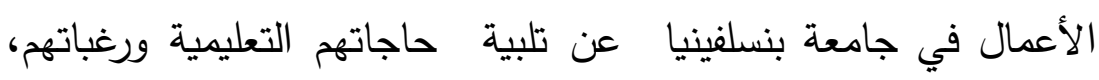

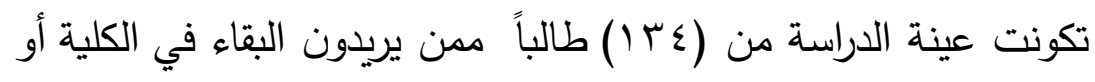

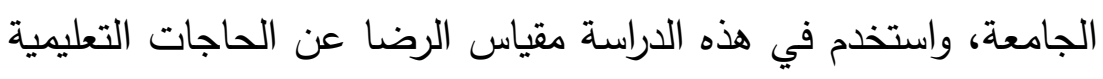

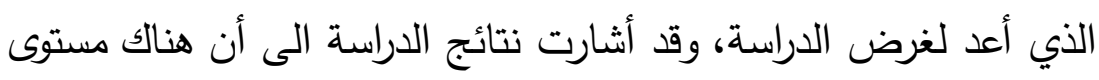


عالي من الرضا حول تلبية الجامعة لحاجاتهم التعليمية ورغباتهم، كما

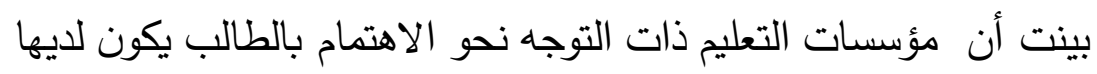

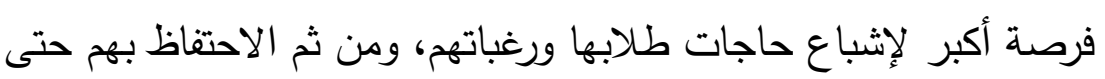
تخرجهم. منهج الدراسة بما أن الدراسة الحالية سعت للتعرف على درجة رضا طلبة جامعة عمان الأهلية عن خدمات التسجيل فإن المنهج المتبع في الدراسة هوله داته

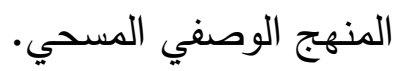
مجتمع الدراسة التهفي تكون مجتمع الدراسة من جميع طلبة جامعة عمان الأهلية في الأردن،

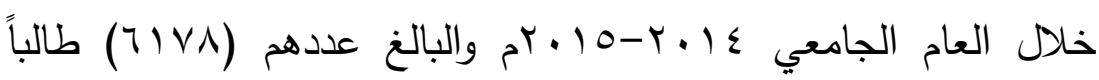
وطالبة حسب إحصائيات جامعة عمان الأهلية خلال العام الجامعي . $r \cdot 10-r \cdot 1 \leq$ عينة الدراسة استخدم أسلوب العينة العشوائية الطبقية في اختيار أفراد العينة وذلك

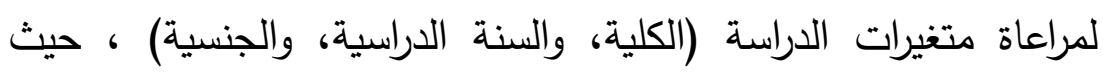

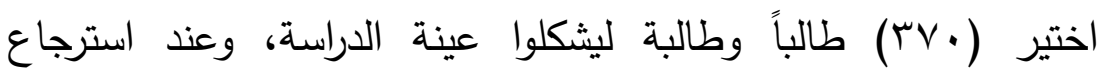

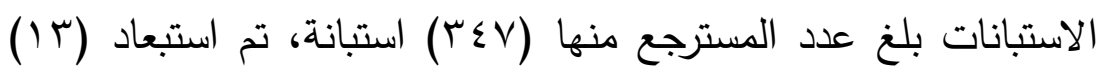
استبانة بسبب عدم اكتمال إجابة المبحوثين عليها، وبالتالي بلغت العينة

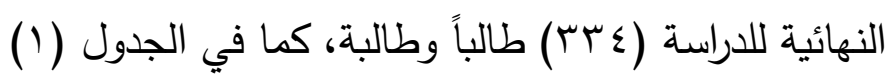
الجدول (1) توزيع أفراد العينة حسب متغيرات اللاراسة 
درجة رضا طلبة جامعة عمان الأهلية عن خدمات التسجيل في جامعتهم د. عونية عطا صوالحة

\begin{tabular}{|c|c|c|c|}
\hline النسبة المئوية \% & العدد العد & الفئات & المتغيرات \\
\hline \%чv.v & rYT & كلية علمية & \multirow[t]{3}{*}{ الكلية } \\
\hline \%rr.r & 1.1 & كلية أدبية & \\
\hline$\% 1 \ldots$ & צחי & المجموع & \\
\hline$\%$ \%.^ & IrT & سنة أولى & \multirow[t]{5}{*}{ لسنة الدراسية } \\
\hline$\%$ \% \&.r & 11 & سنة ثانية & \\
\hline$\% \backslash \wedge . r$ & 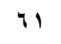 & سنة ثالثة & \\
\hline$\%$ १v.v & 09 & سنة رابعة فأكثر & \\
\hline$\% 1 \ldots$ & בזr & المجموع & \\
\hline$\%$ \%.^ & Irr & أردني & \multirow[t]{3}{*}{ الجنسية } \\
\hline$\% ч . . r$ & $r+1$ & غير أردني & \\
\hline$\% 1 \ldots$ & צ זr & المجموع & \\
\hline
\end{tabular}

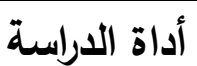

تم استخذام الاستبانة كأداة للدراسـة، وذلك لملاءمتها لطبيعـة هذه الدراسة، بغرض جمع المعلومات والبيانات والإجابة عن التسائلات.

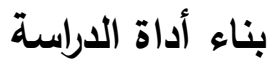

لتحقيق هدف الدراسة المتعلق بالتعرف على درجة رضا طلبة جامعة عمان الأهلية عن خدمات التسجيل ، قامت الباحثة بالاستعانة بالأدب النظري المتعلق بموضوع الدراسة كالآتي: الاستعانة بالدراسات السابقة، وذلك بالرجوع إلى قواعد البيانات ورسائل

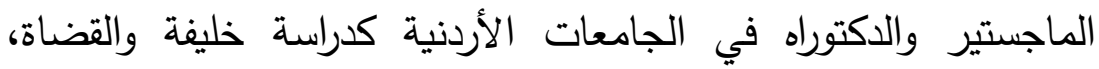

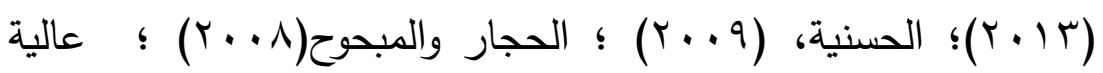

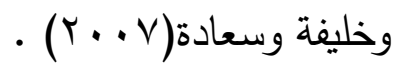
وفي ضوء ما سبق تم التوصل إلى مجموعة من الفقرات تمثلّل اهم خدمات التسجيل وكانت موزعة على مجالين فرعيين، هما: إجراءات التسجيل ، والعاملين في التسجيل. وقد صُمدت الاستجابة على أداة الدراسة، وفق مقياس ليكرت Lekert

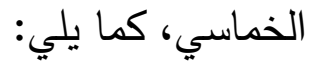




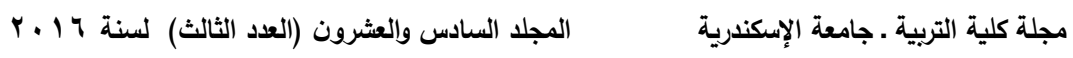

$$
\text { - بدرجة كبيرة جداً (0) درجات.- بدرجة كبيرة (ع) درجات. - برجة }
$$

$$
\text { - بدرجة ضعيفة (درجتان). - بدرجة ضعيفة جداً (درجة واحدة). }
$$

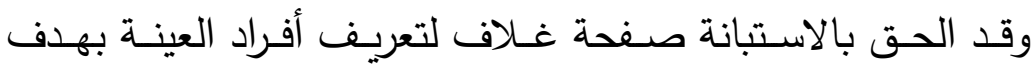
الدراسة، ومجالاتها. كما تضمنت الاستبانة إرشادات عامة لتوضيح كيفية الإجابة عن فقرات الاستبانة، كذلك تضمنت الاستبانة البيانات الأولية

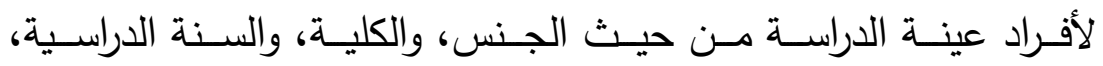
والجنسية.

\section{دلالات صدق وثبات أداة الدراسة}

تم استخراج دلالات صدق وثبات أداة الدراسة قبل تطبيقها على عينة

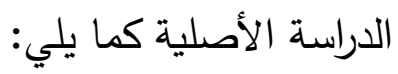

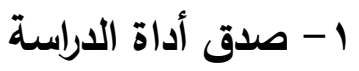

تم التأكد من صدق أداة الدراسة بطريقتين: الأولى قبل التطبيق وتمثلت في صدق المحكمين، والثانية التطبيق على عينة استطلاعية وتمثلت في صدق البناء لأداة الدراسة.

أ- الصدق الظاهري (صدق المحكّمين)

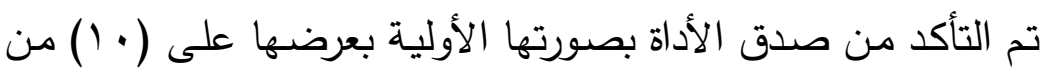

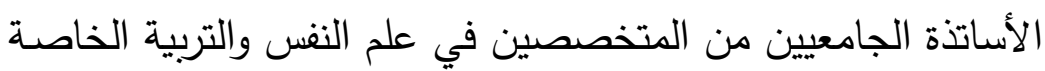
ومدراء مراكز القياس والتقويم في الجامعات و مدير دائرة التسجيل، التهن

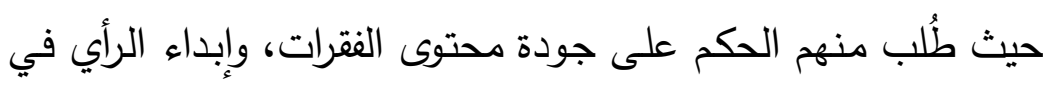
الصياغة اللغوية وسلامتها، ومدى ملائمة الفقرة للمجال الذي اندرجت

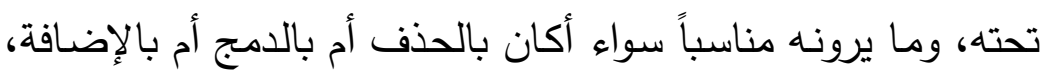

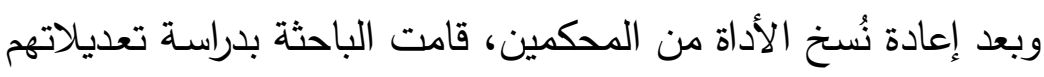

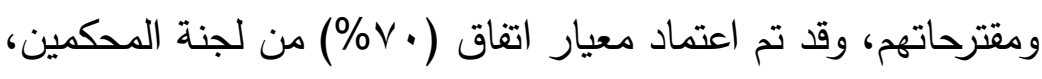

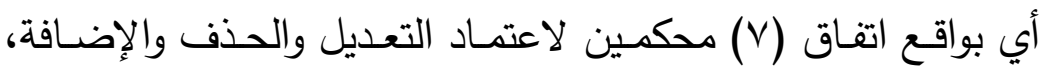


وفي ضــوء ذلــك تـم الأخـذ بـآراء المحكمـين وإجـراء التعـديلات الضرورية، والتي تمثلت في إعادة الصياغة اللغوية لبعض الفقرات.

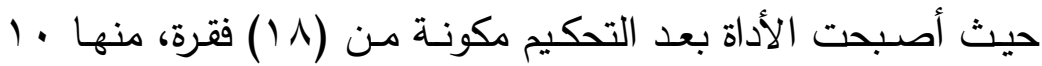

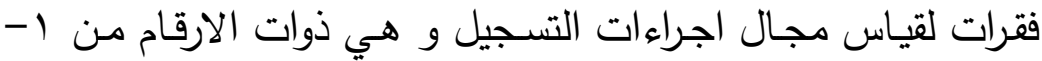

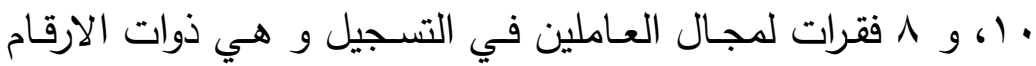

$$
\text { من ||-11 }
$$

\section{ب- صدق الاتساق الاخلي لأداة الدراسة}

بهدف التأكد من صدق الاتساق الداخلي لأداة الدراسـة بعد الانتهاء

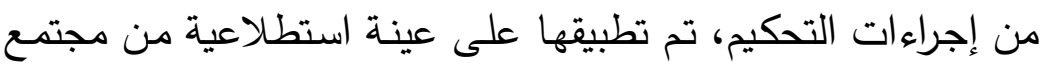

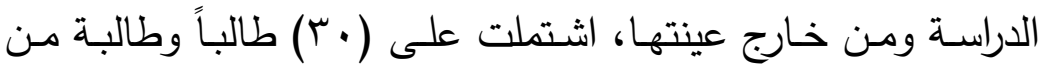

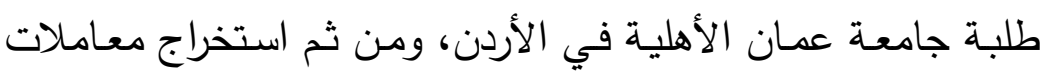

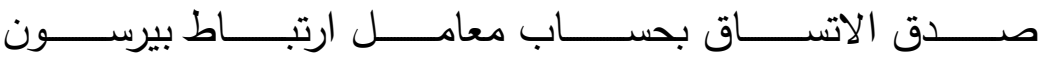
بين كل فقرة من الفقرات مع المجال الواردة (Pearson Correlation) فيه، لإظهار مدى اتساق الفقرات في قياس المجال الواردة فيه، وقد بلغت قيم معاملات الارتباط كما في الجدول (r).

الجدول (ץ) قيم معاملات الارتباط لقياس مدى الاتساق الداخلي للفقرات مع الدرجة الكلية للمجال

\begin{tabular}{|c|c|c|c|}
\hline \multicolumn{4}{|c|}{ خدمات التسجيل } \\
\hline \multicolumn{2}{|c|}{ العاملين في التسجيل } & \multicolumn{2}{|c|}{ إجراءات التسجيل } \\
\hline معامل الارتباط & رقم العبارة & معامل الارتباط & رقم العبارة \\
\hline "**.人५ & 11 & $* * \cdot A \cdot \wedge$ & 1 \\
\hline **..Arr & ir & $* * . . \vee १ १$ & $r$ \\
\hline$* * . .91$. & $1 \%$ & $* * . . \wedge 19$ & $r$ \\
\hline$* * . . \wedge \leqslant V$ & $1 \varepsilon$ & **..Vฯ & $\xi$ \\
\hline$* * . . \wedge 9 \vee$ & 10 & צ זום. "*" & 0 \\
\hline$* * . . \wedge \leqslant V$ & 19 & "*..Arr & 7 \\
\hline$* * . . \wedge \leqslant 0$ & IV & $* * . . \vee \neg \wedge$ & $\mathrm{v}$ \\
\hline
\end{tabular}




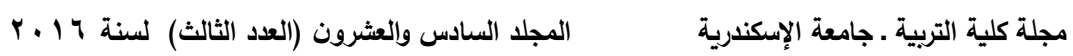

\begin{tabular}{|c|c|c|c|}
\hline$* *$ *.VAI & 11 & $* * . \wedge \backslash \wedge$ & $\wedge$ \\
\hline & & ***. . TV. & 9 \\
\hline & & *** . & 1. \\
\hline
\end{tabular}

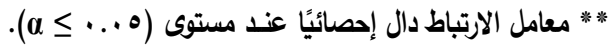

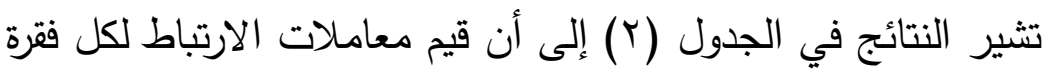

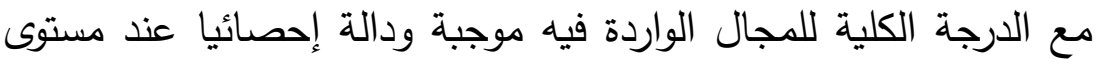
الدلالة (0... فيه. وفي ضوء نتائج الاتساق الداخلي لم يتم حذف أية فقرة من فقرات الى التهات

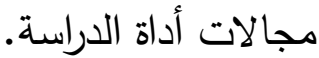
r

بعد التحقق من صدق الاتساق لأداة الدراسة، تم استخراج معاملات

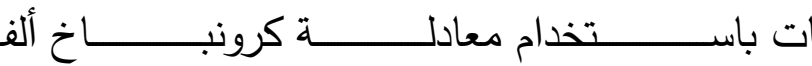
الثب

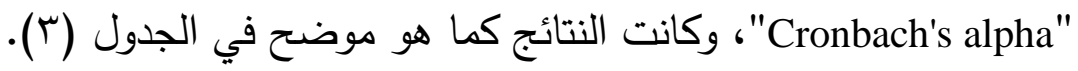
الجدول (ץ) معاملات الثبات لمجالات أداة اللاراسة باستخام معادلة كرونباخ ألفا

\begin{tabular}{|c|c|c|c|}
\hline معامل الثبات & عدد الفقرات & المجالات الفرعية & المجال ل \\
\hline$\cdot .9 \cdot \varepsilon$ & 1. & إجراءات التسجيل & \multirow[t]{3}{*}{ خدمات التسجيل } \\
\hline $.94 \leq$ & $\wedge$ & العاملين في التسجيل & \\
\hline 194 & 11 & خدمات التسجيل (الكلي) & \\
\hline
\end{tabular}

وتعدّ معاملات الثبات مناسبة لأغراض الدراسة الحالية حيث بلغت قيمته للارجة الكلية لمجال خدمات التسجيل (اب9..)، ومن هنا يمكن وصف إدارة الدراسة هذه بالثبات العالي، وأن البيانات التي تم الحصول عليها من خلال تطبيق أداة الدراسة تخضع لدرجة مقبولة من الاعتمادية ويمكن الوثوق بصحتها.

وقد احتوت الأداة بصورتها النهائية على فقرات إيجابية وأخرى سالبة

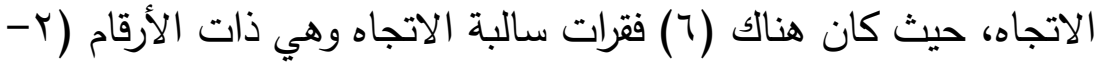
ب-乏-0-11) في مجال خدمات التسجيل، في حين كانت باقي الفقرات 
موجبة الاتجاه. وقد تم مراعاة الصياغة السالبة للفقرات عند تصحيح الأداة بحيث تأخذ الفقرات سالبة الاتجاه العلامة على النحو التالي:

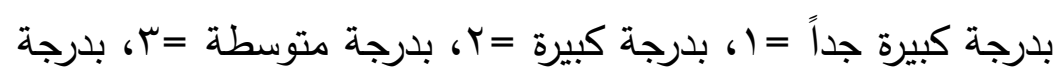

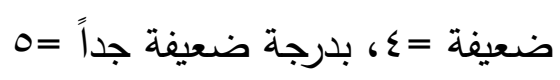

ولأغراض تفسير المتوسط الحسابي لإجابات أفراد العينة، وفقاً لفئات

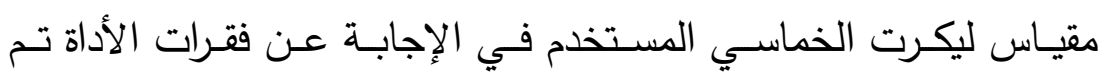

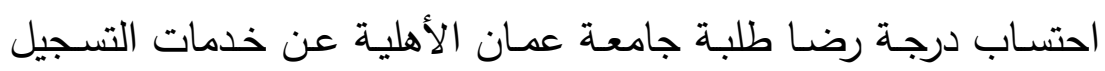
وفق معادلة المدى، حيث تم تحديد طول الفئة وفقاً للمعادلة الآتية: طول الفئة = المدى خ عدد الفئات (مرتفعة، متوسطة، منخفضة) المدى = أكبر قيمة لفئات الإجابة - أصغر قيمة لفئات الإجابة $\varepsilon=1-0=1$ المدى

$$
\text { وبالتالي يكون طول الفئة= ع ٪ }
$$
وهكذا تصبح الأوزان على النحو الآتي:

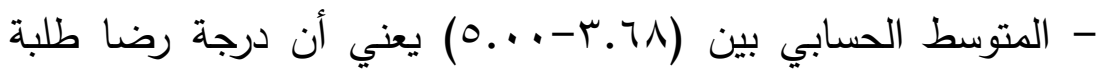

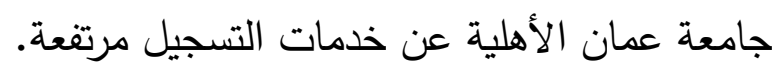

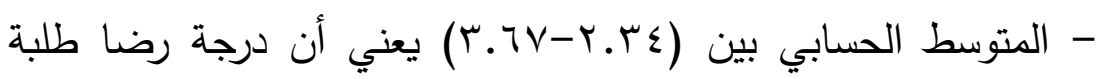

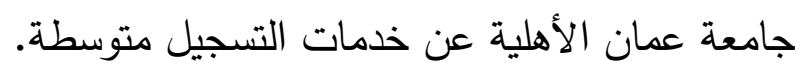

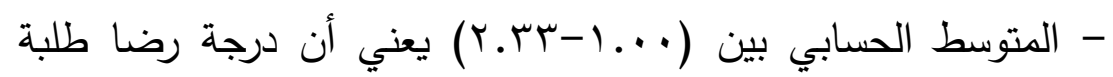
جامعة عمان الأهلية عن خدمات التسجيل منخفضة. متغيرات الدراسة أولاً: المتغيرات التصنيفية : الكلية: ولها فئتان (كلية علمية، كلية أدبية)

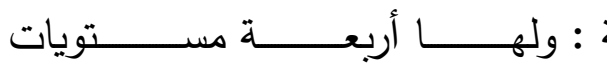
تونة الدراسـ

(سنة أولى، سنة ثانية، سنة ثالثة، سنة رابعة فأكثر)

$$
\text { الجنسية : ولها فئتان (أردني، غير أردني) }
$$


ثانياً: المتغير التابع:

درجة رضا طلبة جامعة عمان الأهلية عن خدمات التسجيل

\section{المعالجات الإحصائية}

تم إجراء المعالجـات الإحصـائية باسـتخدام الأسـاليب الإحصـائية

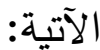

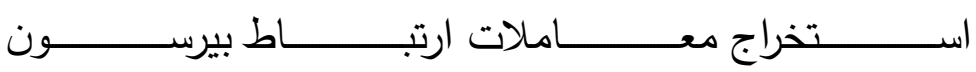

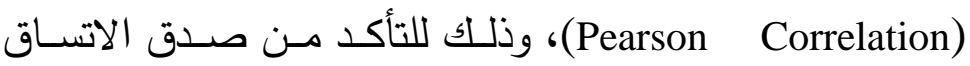

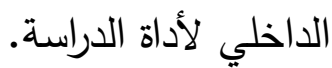

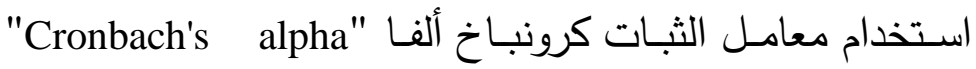
لقياس ثبات أداة الدراسة. هاسخدام المتوسطات الحسابية والانحرافات المعيارية للإجابة عن السؤالين الأول والثاني المتعلقين بالكثف عن درجة رضات رابـا طلبة جامعة عمان الأهلية عن خدمات التسجيل من وجهة نظرهم. تققلة

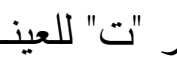

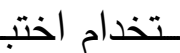

للكثف عن الفروق بين (Independent Samples T-test) تقـديرات الطلبـة لارجـة رضـاهم عـن خـدمات التسـجيل تبعـاً لمتغيرات والكلية والجنسية، في سؤال الدراسة الثاني.

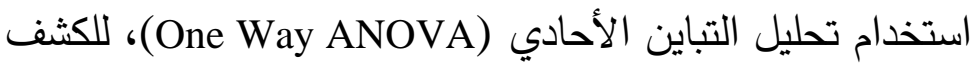

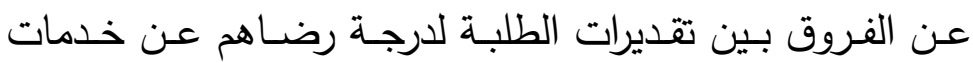
التسجيل تبعاً لمتغير السنة الدراسية، في سؤال الدراسة الثاني. نتائج الاراسـة

نتائج الإجابة عن السؤال الأول: " ما درجة رضا طلبة جامعة عمان الأهلية عن خدمات التسجيل من وجهة نظرهم "؟ للإجابة عن هذا السؤال تم احتساب المتوسط الحسابي، والانحراف المعياري والترتيب لإجابات طلبة جامعة عمان الأهلية على مجالي أداة 
الدراسة الفرعيين اللذان يقيسان درجة رضا الطلبة عن خدمات التسجيل (إجراءات التسجيل، العاملين في التسجيل) بشكل عام،. ويبين الجدول (ع) المتوسطات الحسابية والانحرافات المعيارية والترتيب لتقديرات عينة

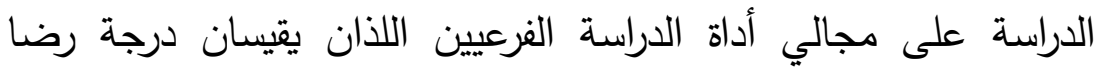
الطلبة عن خدمات التسجيل بشكل عام. الجدول (ء) المتوسطات الحسابية والانحرافات المعيارية لارجة رضا طلبة جامعة عمان الأهلية عن

\begin{tabular}{|c|c|c|c|c|}
\hline درجة الرضا & الترتيب & الانحراف المعياري & المتوسط الحسابي & المجالات \\
\hline متوسطة & $r$ & $\cdots \otimes V$ & $r . \leqslant r$ & إجراءات التسجيل \\
\hline متوسطة & 1 &.$v_{1}$ & r.or & التعاملين في \\
\hline متوسطة & - & .04 & $r . \varepsilon V$ & خلتسجيل \\
\hline
\end{tabular}

يشير الجدول (ع) إلى أن تقديرات طلبة جامعة عمان الأهلية لدرجة رضاهم عن خدمات التسجيل بشكل عام جاءت ضمن الدرجة المتوسطة، إذ بلغ المتوسط الحسابي لتقديرات أفراد العينة على خدمات التسجيل

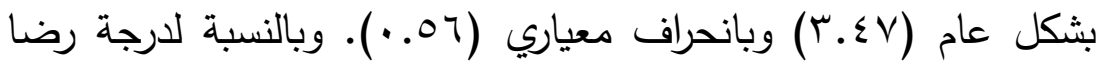
طلبة جامعة عمان الأهلية عن خدمات التسجيل في المجالين الفرعيين، فقد جاء مجال العاملين في التسجيل في الترتيب الأول بمتوسط حسابي

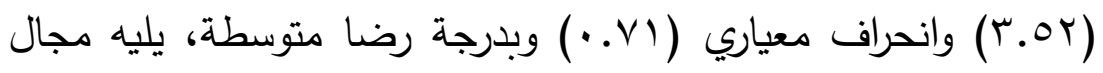

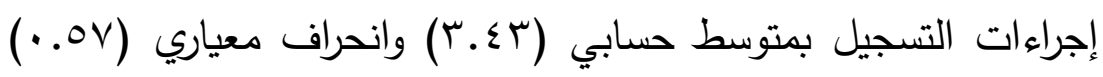
وبدرجة رضا متوسطة.

وربما تفسرهذه النتائج بعدم كفاية خدمات التسجيل سواء في مجال اجراءات التسجيل أو مجال العاملين في التسجيل في تلبية حاجاتهم

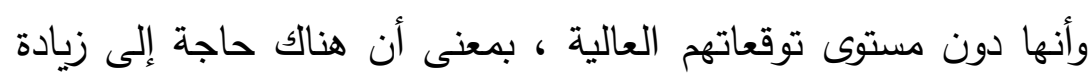


الاهتمام بخدمات التسجيل التي يعبر عنها الطلبة نظراً أهميتها في تحقيق الجودة في التعليم الجامعي. تتفق نتائج هذه الدراسة مـع نتائج كل من دراسات: صوالحة

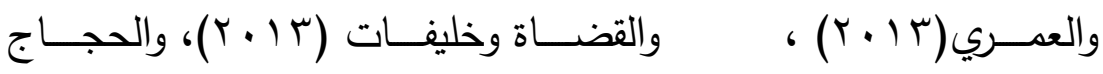
والمبحوح( 2008 ) التي بينت نتائجها أن المستوى العام لرضا الطلبة عن وان والن

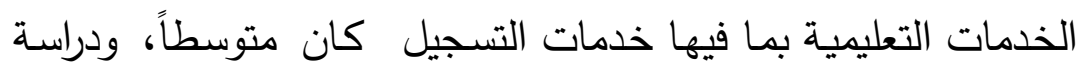
الحسنية ( 2009 ) التي بينت نتائجها أن المستوى العام لرضا طلبة كلية الاقتصاد في جامعة حلب عن الخدمات التعليمية بما فيها خدمات التسجيل للكلية كان (متوسطا) في بعض المجالات ومنخفضاً في مجالات أخرى،. ولا تتفق هذه النتيجة مع نتائج كل من دراسات :عالية

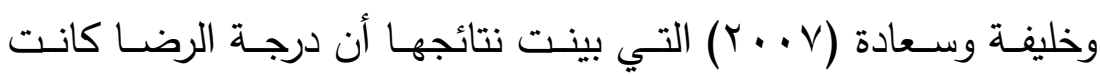
ضعيفة، ودراسـة اوألكو باكال وأخرين ( 2005 ) ) ، ودراسـة كارا

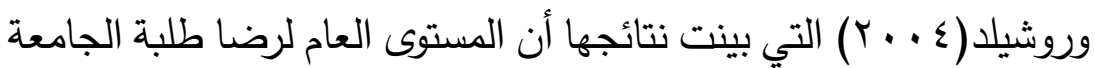
كان عالياً . نتائج الإجابة عن السؤال ال ثاز حي: "هل توجد فروق ذات دلالة

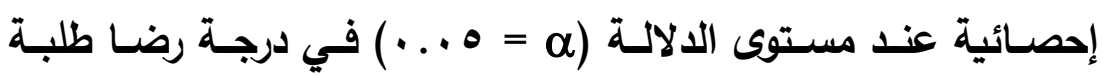
جامعة عمـان الأهلية عن خدمات التسجيل، تعزى لمتغيرات: الكلية،

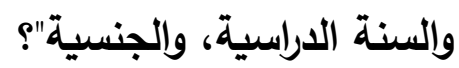
1- النتائج المتعلقة بالفروق في درجة وضلها طلبة جامعة عمان الأهلية عن خذمات التسجيل، تبعاً لمتغير الكلية. تم استخراج المتوسطات الحسابية والانحرافات المعيارية لتقديرات أفراد a

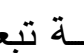
أداة الدراس عل العين

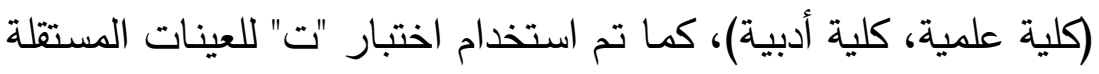
Independent Samples T-test 
درجة رضا طلبة جامعة عمان الأهلية عن خدمات التسجيل في جامعتهم د. عونية عطا صوالحة

الجدول (•) نتائج اختبار (Independent Samples T-test) للكثف عن دلالة الفروق بين تقديرات عينة الدراسة لارجة رضاهم عن خدمات التسجيل تبعاً لمتغير الكلية

\begin{tabular}{|c|c|c|c|c|c|c|c|}
\hline مستوى & قيمة (t) & الانحراف & المتوسط & العدد & الكلية & \multicolumn{2}{|c|}{ مجالات الأداة } \\
\hline \multirow[t]{2}{*}{. rVA } & \multirow[t]{2}{*}{$\therefore \wedge \wedge r-$} &. $.0 \mathrm{~V}$ & r.\&1 & FYY & علمية & \multirow{2}{*}{ إجراء ات التسيل } & \multirow{6}{*}{ خدمات } \\
\hline & &. $.0 \mathrm{~V}$ & $r . \leqslant V$ & 1.1 & أدبية & & \\
\hline \multirow[t]{2}{*}{$\cdots v 1$} & \multirow[t]{2}{*}{$1.1 .9-$} &. .79 & $r . \leqslant \wedge$ & FYY & علمية & \multirow{2}{*}{ العاملين في } & \\
\hline & &.$\vee v 4$ & r.tr & 1.1 & أدبية & & \\
\hline \multirow[t]{2}{*}{ 141 } & \multirow[t]{2}{*}{$1.010-$} &. .00 & r. & YYT & علمية & \multirow[t]{2}{*}{ (الكلي) } & \\
\hline & &. .01 & r.0 & 1.1 & أدبية & & \\
\hline
\end{tabular}

تُظهر المتوسطات الحسابية في الجدول (0) وجود اختلافات ظاهريـة بين تقديرات أفراد العينة لدرجة رضـاهم عن خدمات التسـيل في جامعة عمان الأهلية، وذلك تبعًا لمتغير الكلية (كلية علمية، كلية أدبية)، وقد تم إجـراء تحليـل "T" للعينـات المسـتقلة، للكثـف عـن دلالـة الفـروق بـين تقديرات أفراد العينـة في ضـوء متغير الكلية، حيث أظهرت النتائج أن الفروق بين تقديرات أفراد العينة لدرجـة رضـاهم عن خدمات التسجيل، وواقع الإرشـاد الأكاديمي في جامعـة عمـان الأهليـة، بشكل عـام وفي المجالات الفرعية، لم تكن دالة إحصائياً، إذ تراوحت قيم "T" المحسوبة

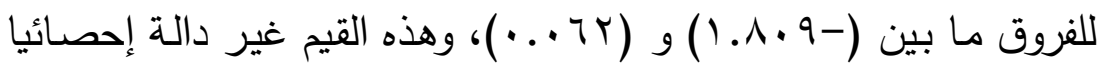
عند مستوى الدلالة المحدد (a $\alpha=0$ وبالتالي يمكن القول إن درجة رضا طلبة الكليات العلمية والكليات الأدبية في جامعة عمان الأهلية عن خدمات التسجيل، بمعنى أن عامل الكلية لا يُعد عاملاً مؤثراً في درجة رضا الطلبة عن خدمات التسجيل في الان

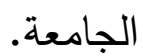

تفسـر الباحثـة هـذه النتيجـة بـالنظرة الثـاملة لواقع عمليـة التســيل بموضـوعية والتـي لا يختلـف بشـأنها أي مـن العناصـر على اختلاف 


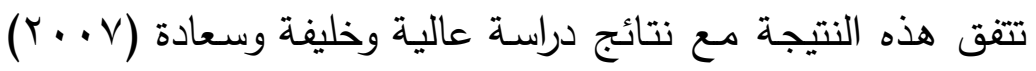
التي بينت نتائجها عدم وجود فروق دالة احصائياً في درجة الرضا تعزى دئه

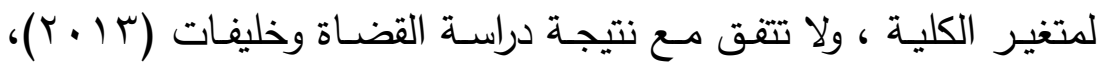

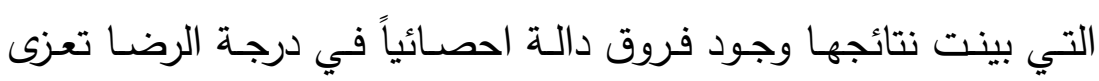
لمتغير الكلية لصالح الكليات الانسانية. r- النتائج المتعلقة بالفروق في درجة رضا طلبة جامعة عمان الأهلية عن خدمات التسجيل، تبعاً لمتفير السنة الدراسية. تم استخراج المتوسطات الحسابية والانحرافات المعيارية لتقديرات أفراد

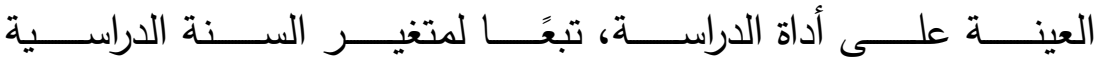

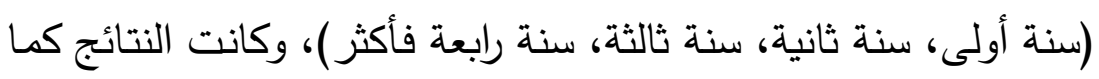

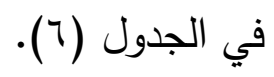
الجدول (؟) المتوسطات الحسابية والانحرافات المعيارية لتقديرات عينة الدراسة لارجة رضاهم عن

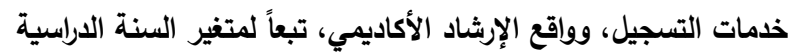

\begin{tabular}{|c|c|c|c|c|c|c|}
\hline \multicolumn{4}{|c|}{ السنة الدراسية } & الإحصائيات & \multirow{2}{*}{\multicolumn{2}{|c|}{ مجالات الأداة }} \\
\hline سأكثر & سنة ثالثة & سنة ثانية & سنة أولى & الوصفية & & \\
\hline$r .0 \varepsilon$ & $r . \varepsilon r$ & $r . \leqslant \varepsilon$ & r.rv & المتوسط الحسابي & \multirow{2}{*}{ إلجراءل } & \multirow{6}{*}{ خلتمبل } \\
\hline $.0 \%$ & . or & rit &. $.0 \mathrm{~V}$ & الانحراف المعياري & & \\
\hline$r . \leqslant 0$ & $r . \varepsilon r$ & r.00 & $r .01$ & المتوسط الحسابي & \multirow[t]{2}{*}{ العاملين في التسجيل } & \\
\hline 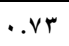 & . . Tr & . v. & . vo & الانحراف المعياري & & \\
\hline r.o. & $r . \& Y$ & r. $\leqslant 9$ & $r . \xi v$ & المتوسط الحسابي & \multirow[t]{2}{*}{ (الكلي) } & \\
\hline .04 & .01 & .01 &. .01 & الانحراف المعياري & & \\
\hline
\end{tabular}

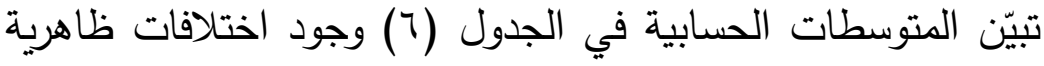
بين تقديرات أفراد العينة لدرجة رضاهم عن خدمات التسجيل وفقاً لمتغير

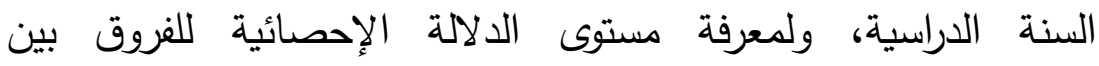

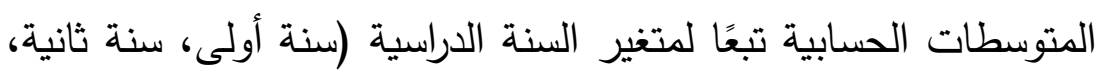




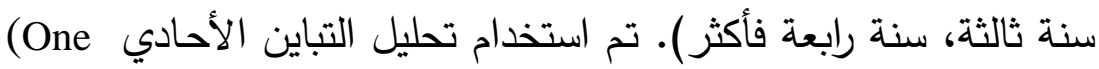
Way ANOVA)

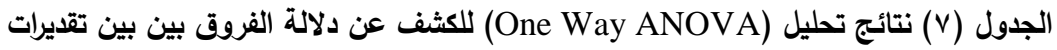

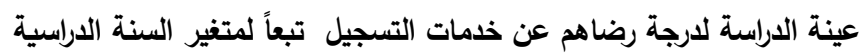

\begin{tabular}{|c|c|c|c|c|c|c|c|}
\hline مستوى & قيمة "f" & متوسط & درجات & مجموع & مصدر التباين & \multicolumn{2}{|c|}{ مجالات الأداة } \\
\hline \multirow{3}{*}{ זוז. } & \multirow{3}{*}{1.191} & ma & & $1)^{2}$ & & \multirow{3}{*}{ التسرجيل } & \multirow{9}{*}{ ختسجيل } \\
\hline & & מצr. & שr. & 1.7 .081 & داخل المحموعات & & \\
\hline & & & שrt & I.V.VY & المجموع & & \\
\hline \multirow[t]{3}{*}{.$\leqslant r \wedge$} & \multirow[t]{3}{*}{. .949} &..$\leqslant V Y$ & $r$ & $1 . \$ 17$ & بين المجموعات & \multirow{3}{*}{ التسي } & \\
\hline & & .01. & rr. & $|\neg \Lambda . r| \varepsilon$ & داخل المجموعات & & \\
\hline & & & Trt & 179.74. & المجموع & & \\
\hline \multirow[t]{3}{*}{ • } & \multirow[t]{3}{*}{$. r \leqslant Y$} & $\ldots \vee q$ & $r$ & TrTY & بين المجموعات & \multirow[t]{3}{*}{ (الكلي) } & \\
\hline & & . Irr. & שr. & $1.0 .8 \times 4$ & داخل المجموعات & & \\
\hline & & & TrT & $1.0 . V 1 Y$ & المجموع & & \\
\hline
\end{tabular}

تثير النتائج في الجدول (V) إلى عدم وجود فروق دالـة إحصـائيًا

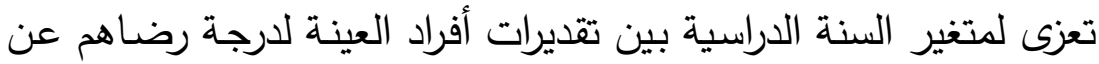

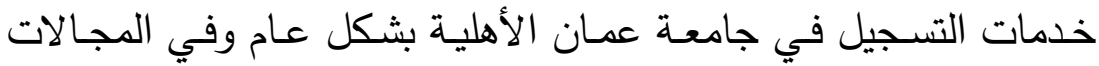

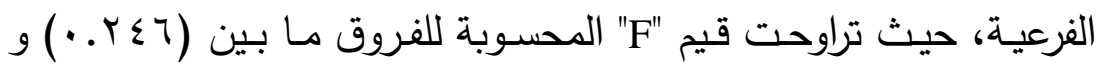

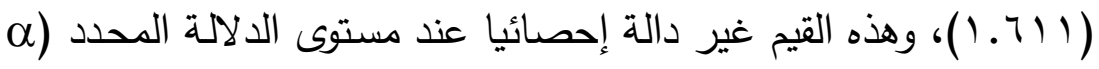

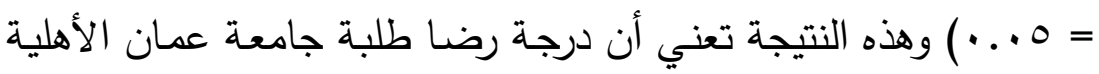

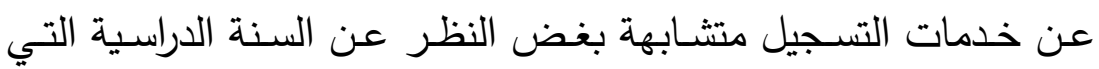

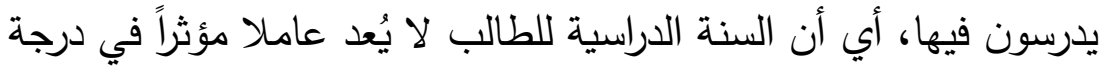
رضا الطلبة عن خدمات التسجيل في جامعة عمان الأهلية. ويمكن تفسير هذه النتيجة في ضوء طبيعة عملية التسجيل التي يخضع لها طلبة الجامعة والتي يتم من خلالها تقديم التوجيه والمساعدة بشكل يكاد يكون متساوٍ إلى حد ما لدى جميع الطلبة على اختلاف سنوات الدراسة.

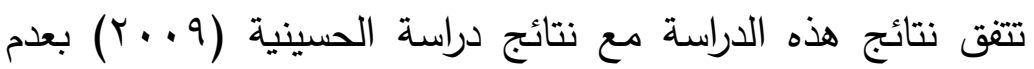

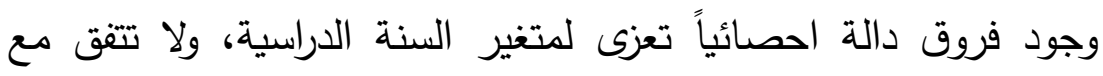




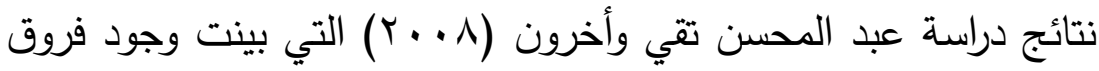
دالة احصائياً تعزى لمتغير السنة الدراسية. r- النتائج المتعلقة بالفروق في درجة رضا طلبة جامعة عمان الأهلية عن خدمات التسجيل تبعاً لمتغير الجنسية. تم استخراج المتوسطات الحسابية والانحرافات المعيارية لتقديرات أفراد

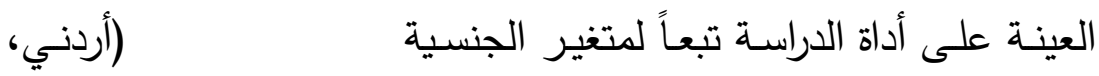

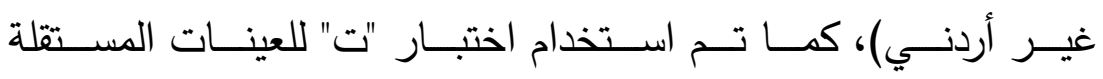
Independent Samples T-test الجدول (^) نتائج اختبار (Independent Samples T-test) للكثف عن دلالة الفروق بين

\begin{tabular}{|c|c|c|c|c|c|c|c|}
\hline مستوى & قيمة (t) & الانحراف & المتوسط & العدد & الجنسية & \multicolumn{2}{|c|}{ مجالات الأداة } \\
\hline \multirow{3}{*}{ 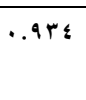 } & \multirow{3}{*}{$\ldots \wedge r-$} & & & & & \multirow{3}{*}{ إلتسراء } & \multirow{7}{*}{ خدمات التسجيل } \\
\hline & &. .04 & r.\& r & $1+r$ & أردني & & \\
\hline & & .01 & $r . \varepsilon r$ & $r+1$ & غير أردني & & \\
\hline \multirow[t]{2}{*}{...4 } & \multirow[t]{2}{*}{1.179} &..$v$. & $r .7$ & $1+r$ & أردني & \multirow{2}{*}{ التسجيل في } & \\
\hline & &.$V Y$ & r. $\leftleftarrows V$ & r. & غير أردني & & \\
\hline \multirow[t]{2}{*}{.rIV } & \multirow[t]{2}{*}{$1 \ldots r$} &. .01 & $r .01$ & irr & أردني & \multirow[t]{2}{*}{ (الكلي) } & \\
\hline & & .00 & r. $\leqslant 0$ & $r+1$ & غير أردني & & \\
\hline
\end{tabular}

تبين المتوسطات الحسابية في الجدول (^) وجود اختلافات ظاهريـة بين تقديرات أفراد العينة لدرجة رضاهم عن خدمات التسجيل في جامعة

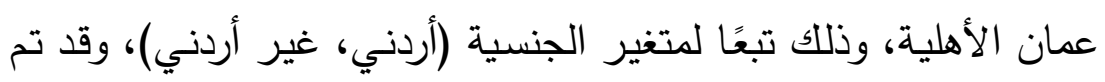

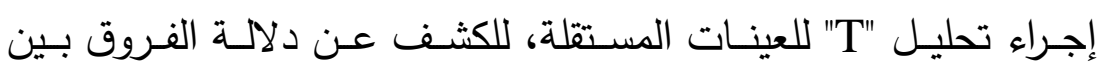

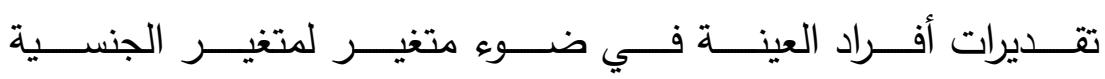
(أردني، غير أردني)، حيث أظهرت النتائج أن الفروق بين تقديرات أفراد

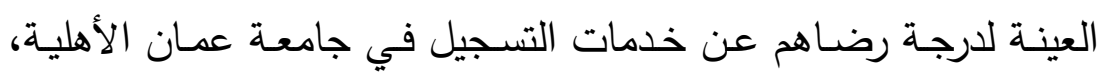

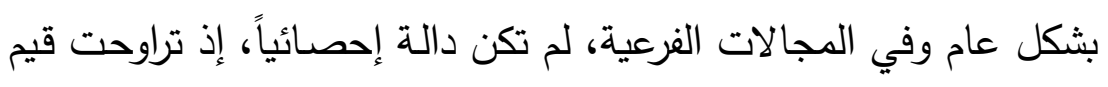




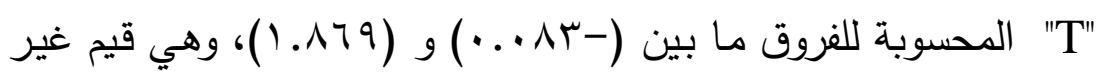

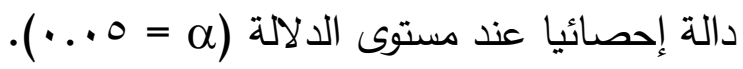

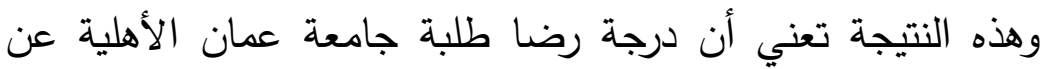
خدمات التسجيل متشابهة بغض النظر عن جنسيتهم. ويمكن تفسير هذه النتيجة في ضوء طبيعة عملية التسجيل التي يخضع لها طلبة الجامعة والتي يتم من خلالها تقديم التوجيه والمساعدة بشكل يكاد يكون متساوٍ إلى حئى حد ما لدى جميع الطلبة على اختلاف جنسياتهم أي أن جميع الطلبة الأردنيين وغير الأردنيين يحظون بنفس الاهتمام.

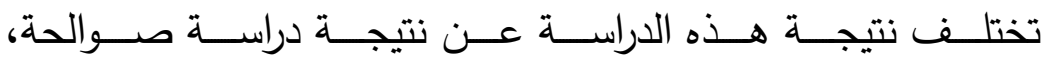

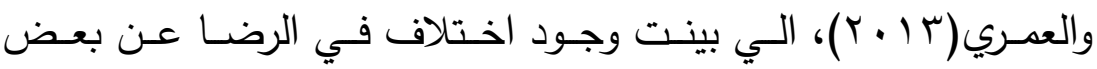

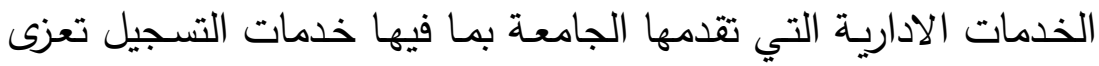
لمتغير الجنسية. التوصيات

1. العمل على تعميم نتائج هذه الدراسة لدى صانعي القرار والجهات ذات العلاقة في جامعة عمان الأهلية للاستفادة منها في تحقيق ندانج درجة عالية من الرضا للطلبة، واتخاذ القرارات المناسبة لتقييم جودة الخدمات المقدمة في الجامعة مما يساعد على رفع مستواها في مصاف الجامعات المرموقة محلياً واقليمياً.

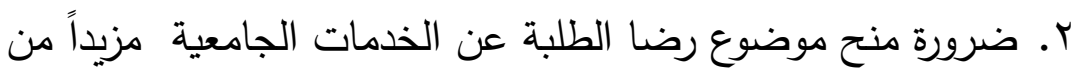

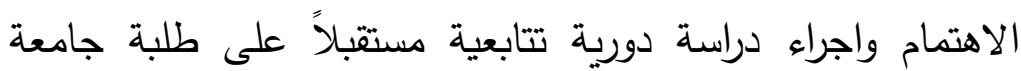
عمان الأهلية للتعرف على مدى ثبات أو تغير نتائج الدراسة.

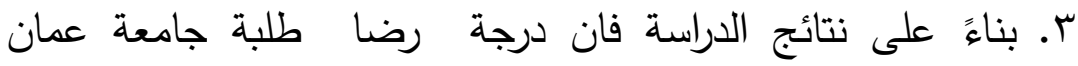
الأهلية كان متوسطاً في عملية التسجيل وهذا يحتم تطوير عملية التسجيل وسد الفجوة بين ما هو موجود وما هو مأمول. 
المجلد السادس والعشرون (العدد الثالث) لسنة 7 ا ب
مجلة كلية التربية ـ جامعة الإسكندرية 
المصادر والمراجع

\section{المراجع العربية}

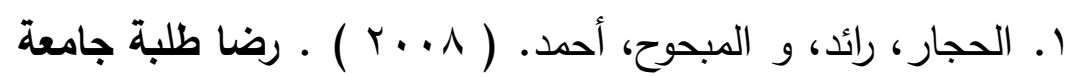
الأقصى عن جودة الخدمات في عمليات التسجيل والإرشاد الأكاديمي. فلسطين، جامعة الأقصى.

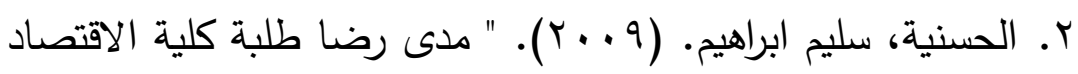
في جامعة حلب عن مستوى الأداء الإداري والأكاديمي لكليتهم".

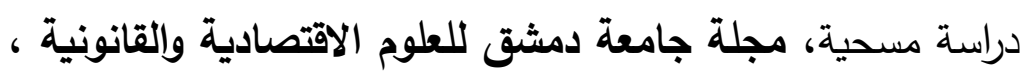

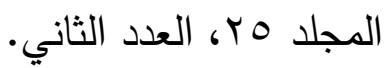

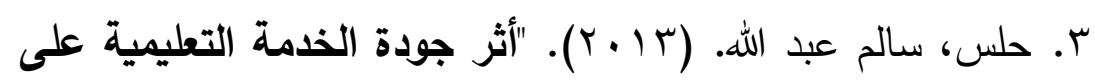
رضى الطلبة".دراسة تطبيقية على طلبة الماجستير بالجامعة الإسسلامية. فلسطين، جامعة غزة. ـ. شهاب، أحمد، (71911) ، مشكلات التسجيل في الجامعات الأردنية

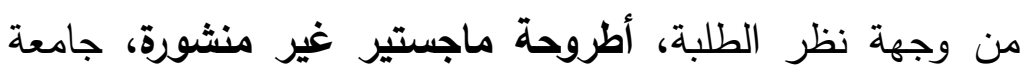

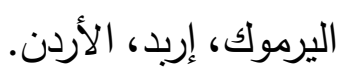

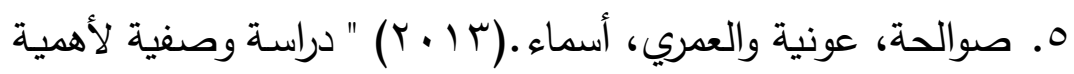
الحاجات الأكاديمية في جامعة عمان الأهلية ومستوى رضا الطلبة 
عن مدى تحقق هذه الحاجات" مجلة الجامعة الإسـلامية للاراسـات

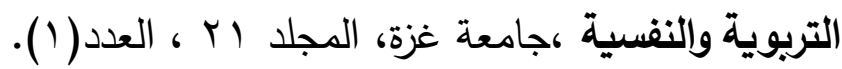
7. عالية،حمح كمال و خليفة، غازي جمال و و سعادة، جودت

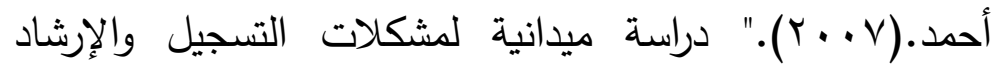
الأكاديمي الجامعي". دراسات، العلوم التربوية، المجّلد 34 ،

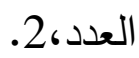

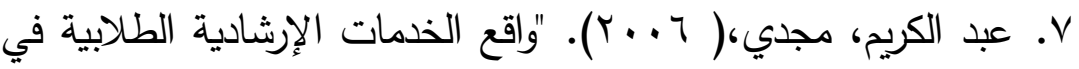

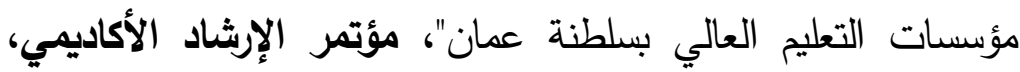
جامعة الرستاق، سلطنة عمان.

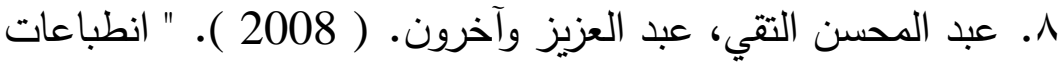
الطلبة عن جودة الخدمة في جامعة الكويت والتعليم التطبيقي والجامعات الخاصة". مجلة العلوم الاجتماعية، المجلد 36 العدد3 . 3

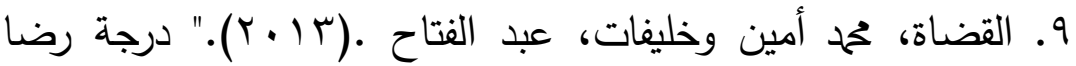
طلبة جامعة مؤتة عن الخدمات الجامعية من وجهة نظرهم". مجلة المنارة، جامعة ال البيت،المجلد 9 (1، العدد (1) المراجع الإنجليزية

10. Baykal, Ulku et al (2005). Determining Student Satisfaction in a Nursing College. Nurse Education Today, 25, (4), 255-262.

11. Bolliger, D. \& Martindale, T. (2004), "Key Factors for Determining Student Satisfaction in Online Courses", International journal of E-Learning. Vol.3, No. 1: 61-67.

12. Kara,A. \& DeShield, O. W. (2004). Business Student Satisfaction, Intentions and Retention in Higher Education: An Empirical Investigation. MEQ,Vol 3. 
درجة رضا طلبة جامعة عمان الأهلية عن خدمات التسجيل في جامعتهم د. عونية عطا صوالحة

13. McGhie, V.F. 2009. Teaching for a New Generation of Students: Understanding the Needs and Challenges of First-year Students in the Learning Process. Peer-reviewed, International Journal of Learning, Common Ground, Australia, $16(9): 719-732$.

الملخص

هدفت هذه الدراسـة تعرف درجة رضـا طلبة جامعـة عمان الأهلية

عن اجراءات التسجيل من وجهة نظرهم، وعلاقة درجة الرضا بمتغيرات : نوع الكلية، السنة الدراسـية ، والجنسية. اسـتخدمت استبانة مكونـة مـن

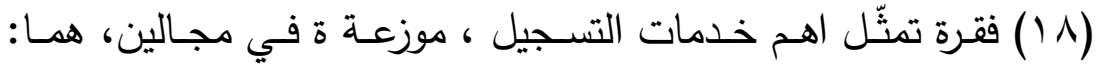
إجراءات التسـيل، والعاملين في التسجيل. صُمدت الاستجابة على أداة الدراسـة، وفق مقياس ليكرت Lekert الخماسي. طبقت على عينة مؤلفة من ( rV• فرداً اختيرو بطريقة عشوائية.

وكانـت نتيجـة الدراسـة أن تقديرالطلبـة لدرجـة الرضـا عن خـدمات التسـجيل في الجامعـة عمومـاً كـان ( متوســاً ) ، وأوضـحت نتـائج الدراسة عدم وجود فروق دالة إحصائياً تعزى لمتغيرات نوع الكلية، السنة الدراسية ، والجنسية .في درجة الرضا عن اجراءات التسجيل .

الكلمـات الدالة: ، خدمات التسـجيل، درجة الرضـا ، ، جامعـة عمـان 


\begin{abstract}
This study aimed at measuring the degree of $\mathrm{Al}$ Ahleyya Amman University Students' satisfaction about registration services from their point of view, and the relationship of the degree of satisfaction with variables of: gender, type of college, academic year, and nationality .

A questionnaire consisting of (18) items representing the most important aspects of registration services was used and distributed in two areas: registration procedures, and workers in the registry .

The answer of questionnaire was according to the Likert scale Lekert Quintet applied to a sample of 370 individuals choosen randommly .

The results of the study were: the degree of satisfaction with the registration services in the university in general was (moderate). There were no statistically significant differences due to studied variables.
\end{abstract}

Key words: registration services, the degree of satisfaction, Amman Private University 